Check for updates

Cite this: J. Mater. Chem. A, 2021, 9 18102

Received 9th April 2021

Accepted 17th June 2021

DOI: $10.1039 / d 1 t a 02982 g$

rsc.li/materials-a

\section{Engineering membranes with macrocycles for precise molecular separations}

\author{
Tiefan Huang, ${ }^{\text {ab }}$ Mram Alyami, ${ }^{c}$ Niveen M. Kashab*c and Suzana P. Nunes (iD *a
}

Macrocycles are a class of intrinsically porous organic molecules that can host guest molecules selectively. Owing to their diversified porous characteristics, host-guest/supramolecular feature, unique chemical versatility and tunable chemical functionalities, macrocycles are considered fascinating membrane building blocks for advanced and efficient separations. Continuously growing research explorations on macrocycle-based membranes have recently emerged ranging from preparation tactics to applications; however, their significance for membrane separations is far from being fully recognized and understood. Therefore, it is important to timely and systematically summarize the progress of macrocycle-based membranes and provide genuine insight for future studies in this interesting field. In this review, we first discuss the different types of macrocycles used to produce high-quality membranes and elucidate their characteristics. We then focus on fabrication approaches, including blending, surface (or pore) modification, crosslinking and self-assembly by discussing the merits and limitations of each approach. We also break-down the different applications of macrocycle-based membranes including water treatment, pervaporation and organic solvent nanofiltration and chiral separation. All separation applications are evaluated and analyzed in terms of current efficiency and future prospects. Most importantly, this review highlights the challenges and opportunities for improving these smart membranes in order to scale-up and translate this promising technology directly into the consumer market.
${ }^{a}$ King Abdullah University of Science and Technology (KAUST), Nanostructured Polymeric Membranes Laboratory, Advanced Membranes and Porous Materials Center, Biological and Environmental Science and Engineering Division (BESE), Thuwal, 23955-6900, Saudi Arabia. E-mail: suzana.nunes@kaust.edu.sa

${ }^{b}$ Functional Membrane Materials Engineering Research Center of Hunan Province, School of Chemistry and Chemical Engineering, Hunan University of Science and Technology, Xiangtan 411201, China
'King Abdullah University of Science and Technology (KAUST), Smart Hybrid Materials (SHMs) Laboratory, Advanced Membranes and Porous Materials Center, Physical Sciences and Engineering Division (PSE), Thuwal, 23955-6900, Saudi Arabia. E-mail: niveen.kashab@kaust.edu.sa

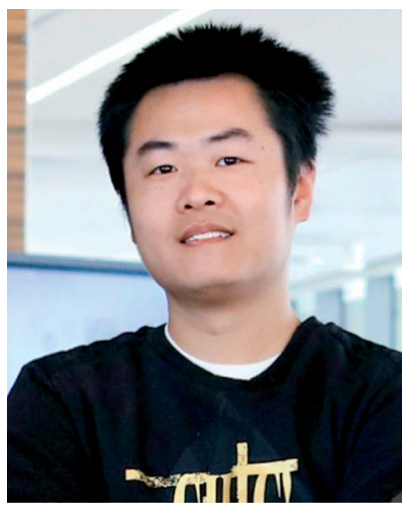

Tiefan Huang received his $P h D$ in Chemical Engineering from Zhejiang University in 2015 under the supervision of Prof. Congjie Gao and Prof. Lin Zhang. Then, he worked as a postdoc under the supervision of Prof. Klaus-Viktor Peinemann and Prof. Suzana P. Nunes at the King Abdullah University of Science and Technology (KAUST). Currently, he is a lecturer at the School of Chemistry and Chemical Engineering of Hunan University of Science and Technology. His research focuses on advanced nanofiltration membranes, and polymeric porous materials.

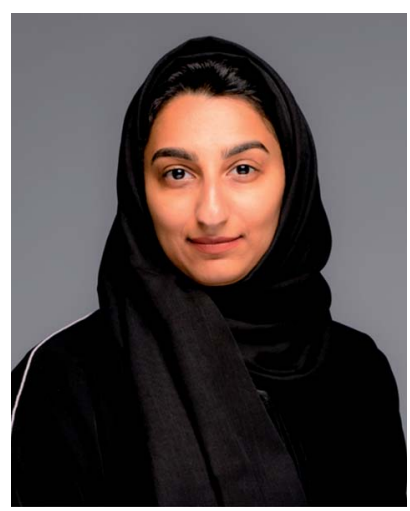

Mram Alyami is a PhD student in Chemical Sciences, under the supervision of Prof. Kashab at the King Abdullah University of Science and Technology (KAUST). Her work focuses on macrocycles, and supramolecular assembly for different applications. 


\section{Introduction}

Separation technology plays a vital role in the chemical industry as well as in our daily life and involves three basic functions: concentration, fractionation, and purification. Although conventional separation and purification processes, such as distillation and evaporation, were developed a long time ago, the accompanying intense energy consumption and large footprint cannot be ignored. Membrane separations, which have the potential to address energy and environmental challenges, have attracted intensive interest over the past few decades. This forward looking technology outperforms other traditional separation technologies in terms of its lower carbon emission, high energy efficiency, continuous operation mode, and small capital investment. ${ }^{1-3}$

So far, many different membranes with dense or porous structures have been developed from conventional amorphous polymers such as polyimide (PI), polyamide (PA), polyacrylonitrile (PAN), poly(ether sulfone) (PES), polysulfone (PSF), poly(viny alcohol) (PVA), polydimethylsiloxane (PDMS), etc. Though these polymer membranes dominate the present separation market, they notably have an intrinsic trade-off relation between permeability and selectivity, which means that highly selective polymeric membranes usually have low permeability and vice versa. ${ }^{4,5}$ This trade-off is as a consequence of the lack of permanent microporosity and the free volume within the membrane microstructure, leading to low solubility and diffusion coefficients for molecule transport. Even more important, the effective paths for molecular transport in most membranes are not strictly uniform. The fine tuning of the pore size and size distribution to promote high sieving control in the nanoscale is still highly challenging. Strategies offering permanent and uniform nanoporosity are important to enable more effective molecular separations..$^{6-8}$ An approach that has led to high expectation is the preparation of membranes fully composed of materials with well-defined microporosity, such as 2D materials, zeolites, metal-organic frameworks (MOFs) and covalent organic frameworks (COFs). ${ }^{9-13}$ However, the fabrication of fully crystalline membranes without defects is highly challenging and hard to scale-up. An easier alternative is the incorporation of microporous materials as additives into the polymer matrix to form mixed-matrix membranes. ${ }^{14}$ These additives can offer intrinsic molecular transport channels to facilitate solvent permeability. The main drawback of discrete additives embedded within a polymer matrix is the poor compatibility between them, which can induce the formation of nonselective voids and decrease the separation performance. Furthermore, if the right combination of permeability for the matrix and fillers is not carefully chosen, poor selectivity would be obtained even with good adhesion between them. Hence, the development and design of new materials with characteristics of well-defined intrinsic microporous structures and tunable pore sizes as membrane building blocks are important for the advance of separation membranes far beyond incremental achievements with concrete perspectives of technical scalability.

Macrocycles constitute a class of organic porous molecules comprising intrinsically porous structures. They have attracted wide interest for host-guest chemistry and have been intensively investigated for decades. ${ }^{15}$ Since the first kind of macrocycle, crown ethers, were reported in the 1960s, many other synthetic macrocyclic molecules, e.g. calixarene, cucurbituril, and pillararenes, ${ }^{\mathbf{1 6 - 1 8}}$ have been created. Research activity is intense in all aspects of macrocyclic chemistry, with special emphasis on molecular recognition and self-assembly processes. In addition to synthetic macrocycles, naturally occurring macrocycles - such as cyclodextrins (CDs)-have been explored as native structures or after further functionalization. ${ }^{\mathbf{1 9 2 0}}$ For decades, due to their unique porous characteristics, host-guest/supramolecular feature, unique chemical versatility and tunable chemical functionalities, macrocycles have received substantial attention for diverse industrial applications, including separation, adsorption, catalysis, sensors, and drug delivery. Similar to 2D materials, zeolites, MOFs and COFs, macrocycles are considered as suitable building blocks for membrane-based separations, which are

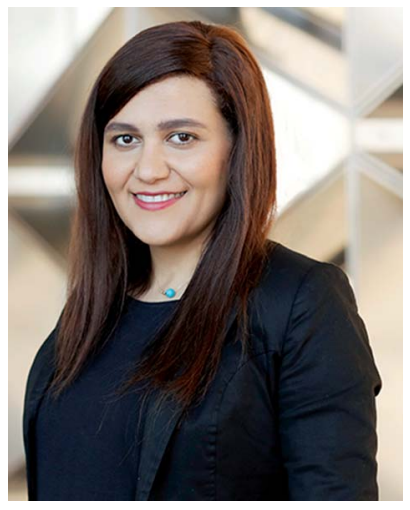

Niveen M. Khashab is Professor and Chair of the Chemical Sciences Program at the King Abdullah University of Science and Technology (KAUST). After her doctoral studies at the University of Florida, she joined Sir Fraser Stoddart's Lab at the University of California, Los Angeles, and then at Northwestern University. Her current efforts focus on intrinsically porous materials (IPMs) for energy intensive separations and supramolecular assembled capsules (SACs) for encapsulation and delivery.

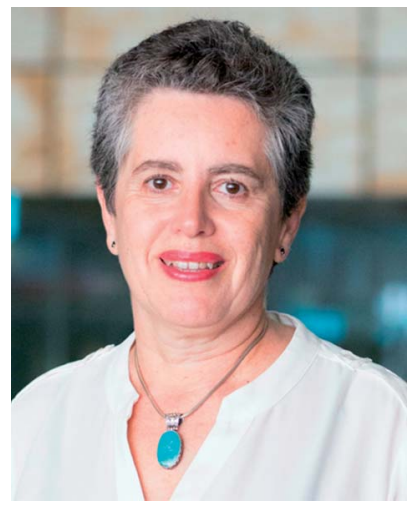

Suzana Nunes is Professor of Chemical and Environmental Science and Engineering and Vice-Provost for Faculty and Academic Affairs at the King Abdullah University of Science and Technology (KAUST). She has a Dr Sci. degree in chemistry from the University of Campinas, Brazil, was postdoc Humboldt Fellow at Mainz University, Germany, and is a Fellow of the Royal Society of Chemistry. She is an expert on polymeric materials, and membrane manufacture and characterization for sustainable separations. 
usually grown on substrates to construct continuous membranes or exploited as fillers to form mixed matrix membranes. Compared with traditional rigid framework particles, the small organic molecule nature of macrocycles may facilitate a homogeneous distribution and the diversity of possible functionalizations may favor interactions with the polymer matrix and allow good compatibility. Even more interesting is the possibility of using the abundant functional sites for further reaction as membrane building units.

Outstanding results for macrocycle-based membranes covering a large spectrum of applications, such as gas separation membranes, liquid separation membranes and membranes for chiral separation are being achieved. However, until now no dedicated report has discussed the status and prospects of macrocycle-based membranes for high-performance separation/purification. We consider it timely to provide a review with focus on this fast-growing area. Herein, we aim to introduce the status and prospects of separations to which macrocycles can contribute or already had an important role. We start with discussion of some representative macrocycles, such as crown ethers, cyclodextrins (CDs), calixarenes, pillararenes, cucurbiturils, and trianglamines (Section 2). Then, we discuss their typical advances in membrane design and construction (Section 3). Optimal methods to synthesize highperformance macrocycle-based membranes with high permselectivity will be emphasized. Separation applications of macrocycle membranes in gas separation, water treatment, pervaporation, organic solvent treatment and chiral separation are subsequently presented, combining the separation mechanism hypothesis in Section 4. In Section 5, new perspectives, opportunities, and challenges are summarized.

\section{Macrocycles for molecular recognition}

Supramolecular macrocycles are well known molecular entities with intrinsic cavities and unique properties that inherently enable them to bind and recognize a specific guest molecule. Supramolecular macrocycles, ${ }^{21}$ such as crown ethers, ${ }^{22}$ cyclodextrins (CDs), ${ }^{23}$ calixarenes, ${ }^{24}$ cucurbiturils (CBs) ${ }^{25}$ pillararenes, ${ }^{26}$ and others ${ }^{27,28}$ are attractive for a wide range of applications, including molecular recognition, ${ }^{29-33}$ nanotechnology, ${ }^{34}$ catalysis, ${ }^{35}$ and drug delivery. ${ }^{36}$ They undergo a variety of interactions, such as electrostatic interactions, charge transfer interactions, hydrogen bonding, $\pi-\pi$ stacking and hydrophobic interactions. ${ }^{37}$ This section focuses on the molecular recognition properties of the macrocycles that are most commonly used for separation applications (Fig. 1). ${ }^{38}$

The factors that make macrocycles attractive for membrane application are given below:

(i) The cavity sizes are in the range of ions and molecules requiring separations, purification and recovery in the desalination, chemical and pharmaceutical industries.

(ii) Their relatively rigid structure and the channel-like structures, like pillar[ $n]$ arenes, can provide pre-formed highly uniform pores for membranes, and potentially separate isomeric organic molecules and ions or act as artificial water channels.

(iii) They can enhance the free-volume and the diffusivity of gases and liquids.

(iv) Macrocycles have functionalities that stimulate hostguest and highly specific interactions with selected molecules, contributing to boosted membrane selectivity.

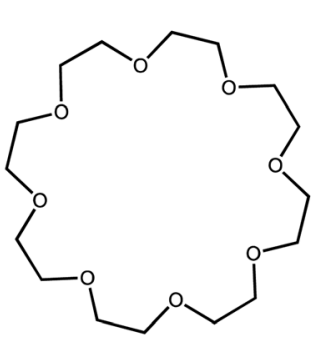

Crown ethers

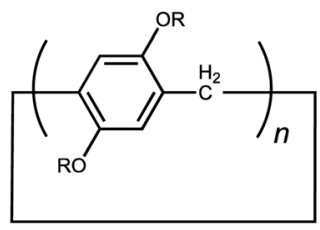

Pillar[n]arenes

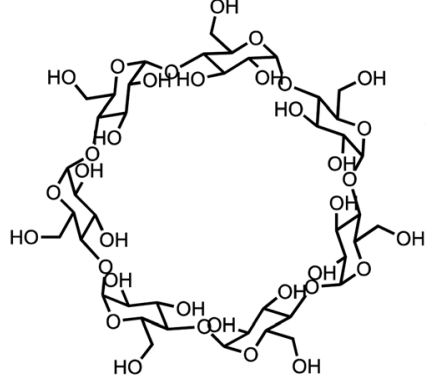

Cyclodextrin

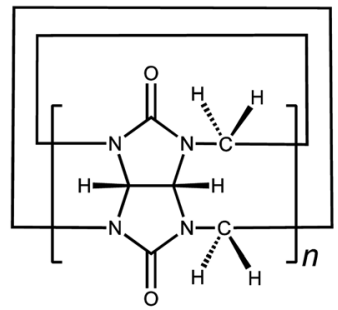

Cucurbiturils

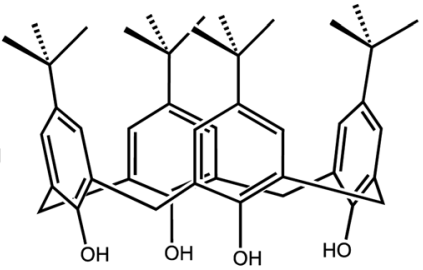

Calix[n]arene

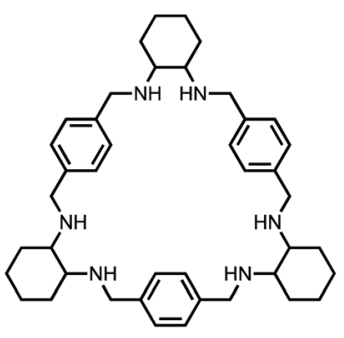

Trianglamine

Fig. 1 General structural formulas of the most common supramolecular macrocycles in separation science. 
(v) Chiral macrocycles could be instrumental in the separations of enantiomers.

Therefore, foreseeable applications enabled by macrocyclebased membranes are ion separations and recovery from different sources, e.g. highly saline lakes and seawater, chiral separations of pharmaceutical products in the biotech industry, separation of isomeric gas molecules in the petrochemical industry.

In this section we describe the characteristics of the most explored macrocycles for separations, in great part demonstrated for selective absorption and molecular recognition. Macrocycle integration into membranes and reported applications are discussed in the next sections.

\subsection{Crown ethers}

Crown ethers, the first generation of synthetic macrocyclic hosts, have been widely utilized to fabricate various supramolecular architectures ${ }^{39,40}$ and received huge interest as complexing agents since their fortuitous discovery by Pedersen in 1967. ${ }^{41}$ Pedersen also demonstrated the ability of this class of molecules to bind other alkali metal ions and an ammonium ion, as extensively reviewed in the literature.

In this review, we focus on the general facts and principles that are useful to understand the scope and the utility of crowns ether for membrane application. The size effect of both the guest and the host plays a major role in the binding selectivity and the stability of cation crown complexes. For example, $\mathrm{K}^{+}$fits nicely within 18-crown- 6 while $\mathrm{Na}^{+}$can be effectively hosted by 15-crown-5. When the macrocycle cavity is too small to fit a cation, the host-guest interactions may be adjusted based on the crown flexibility to allow for the accommodation of the large cations at some energy expense with steric requirements. For example, 12-crown-4 and 15-crown-5 cannot accommodate large cations such as $\mathrm{Rb}^{+}$or $\mathrm{Cs}^{+}$. The complexation of the large cations will then take place outside the macrocycle, placed between two crown molecules, forming a "sandwich complex". On the other hand, when the macrocycle's cavity is larger than the cation, as would be the case with 18-crown-6 or 30-crown-10 complex of $\mathrm{Na}^{+}$, the crown molecules will pucker to achieve the correct $\mathrm{O}-\mathrm{Na}^{+}$binding distances..$^{42}$ Other factors are important, such as the cation charge and type, ${ }^{43,44}$ the number and type of donor atoms, ${ }^{45}$ crown substituents, ${ }^{46}$ and ring flexibility, ${ }^{47}$ as well as the physical properties of a solvent. ${ }^{48,49}$ The complexation usually takes place in a solvent where the complex could crystallize. The equilibrium constant $\left(K_{\mathrm{s}}\right)$ for the complexation reaction indicates how stable the complex is. Generally, the equilibrium constant for the same cation crown complex will be higher in lower polarity solvents. Based on these complexing properties, many crown ether host-guest recognition systems have been reported. For example, the host-guest interaction between benzo-18-crown-6 with primary alkylammonium salts forms pH-responsive supramolecular polymer gels, by protonation and deprotonation of the primary amino group. ${ }^{50}$ In addition, many studies have been reported based on the hostguest interaction of benzo-21-crown-7 with different secondary ammonium salts to construct stimuli-responsive materials benefiting from the reversible nature of noncovalent host-guest interactions. ${ }^{51-55}$ Also, stimuli responsive supramolecular systems have been reported utilizing the host-guest interactions of dibenzo-24-crown-8 with dibenzylammonium salts. ${ }^{56,57}$ On the other hand, the special properties arising from hostguest interactions are not limited to produce stimuli-responsive systems, but could provide cross-linking, suitable to fabricate countless supramolecular networks, such as the host-guest interaction between dialkyl1ammonium salt in polymer 1 in Fig. 2a, which has a polystyrene backbone bearing pendant groups (2,7-diamido-1,8-naphthyridine) (DAN), and benzo-21crown-7 in polymer 2, which consists of a poly (butyl methacrylate) backbone bearing deazaguanosine (DeUG) groups. Quadruple hydrogen-bond interactions between DeUG and DAN to produce a double supramolecular crosslinked polymer gel with expansion-contraction behavior, as shown in Fig. 2a. $\mathrm{K}^{+}$forms a very stable complex with benzo-21-crown-7 disassembling the benzo-21-crown-7/dialkylammonium salt complex and affecting the crosslinking density of the polymer networks. ${ }^{58}$ Liu et al. report the host-guest crosslinking between two glycidyl azide polymers functionalized with dibenzo[24] crown-8 (GTP-DB24C8) and dibenzylammonium salt (GTP-DBA) by click chemistry to produce a supramolecular organogel displayed high elasticity and responsiveness to a variety of stimuli such as temperature, chemical species and acids/bases. ${ }^{59} \mathrm{Wang}$ et al. reported the host-guest interaction between two units of benzo-21-crown-7 linked by the [2]catenane moiety 1 (crosslinker) and secondary ammonium salt grafted polymer 2 to generate a supramolecular polymer network (SPN), as shown in Fig. $2 \mathrm{~b} .^{60}$ Moreover, crown ethers have been used as chiral selectors for enantiomer separation. Chiral crown ethers derived from L-tartaric acid and the 1,1'-binaphthyl group (+)-(18-crown-6)-2,3,11,12-tetra- carboxylic acid and bis-(1,1'binaphthyl)-22-crown-6 were successfully applied in chirotechnology as the HPLC chiral stationary phase (CSP).The efficient enantiomer separation of ester salts and amino acids by these chiral crown ethers occurs due to a host-guest stereoselective complexation. ${ }^{61}$

\subsection{Cyclodextrins}

Cyclodextrins (CDs) constitute the most explored family of naturally occurring host molecules. Cyclodextrins are dissymmetric bucket-shaped cyclic oligosaccharides composed of six, seven, or eight glucopyranose units with hydrophobic cavities $(\alpha-\mathrm{CD}, \beta-\mathrm{CD}$, and $\gamma-\mathrm{CD}) .^{62} \mathrm{CDs}$ have a hydrophilic and polar surface, due to the presence of many hydroxyl groups. These dual-properties opened the utilization of CDs in a wide range of areas, including water treatment, ${ }^{63}$ separation, chromatography, ${ }^{64,65}$ biomedical applications, ${ }^{66,67}$ and catalysis ${ }^{68}$ In this section, we highlight the most significant studies of CDs for separation applications.

The ability of CDs to form host/guest complexes enabled CDs to be effectively utilized for the absorption of small molecules and hydrocarbons separation. Dichtel and co-workers reported porous $\beta$-CD polymers which were utilized for the removal of many organic micropollutants such as pesticides, plastic 
a)
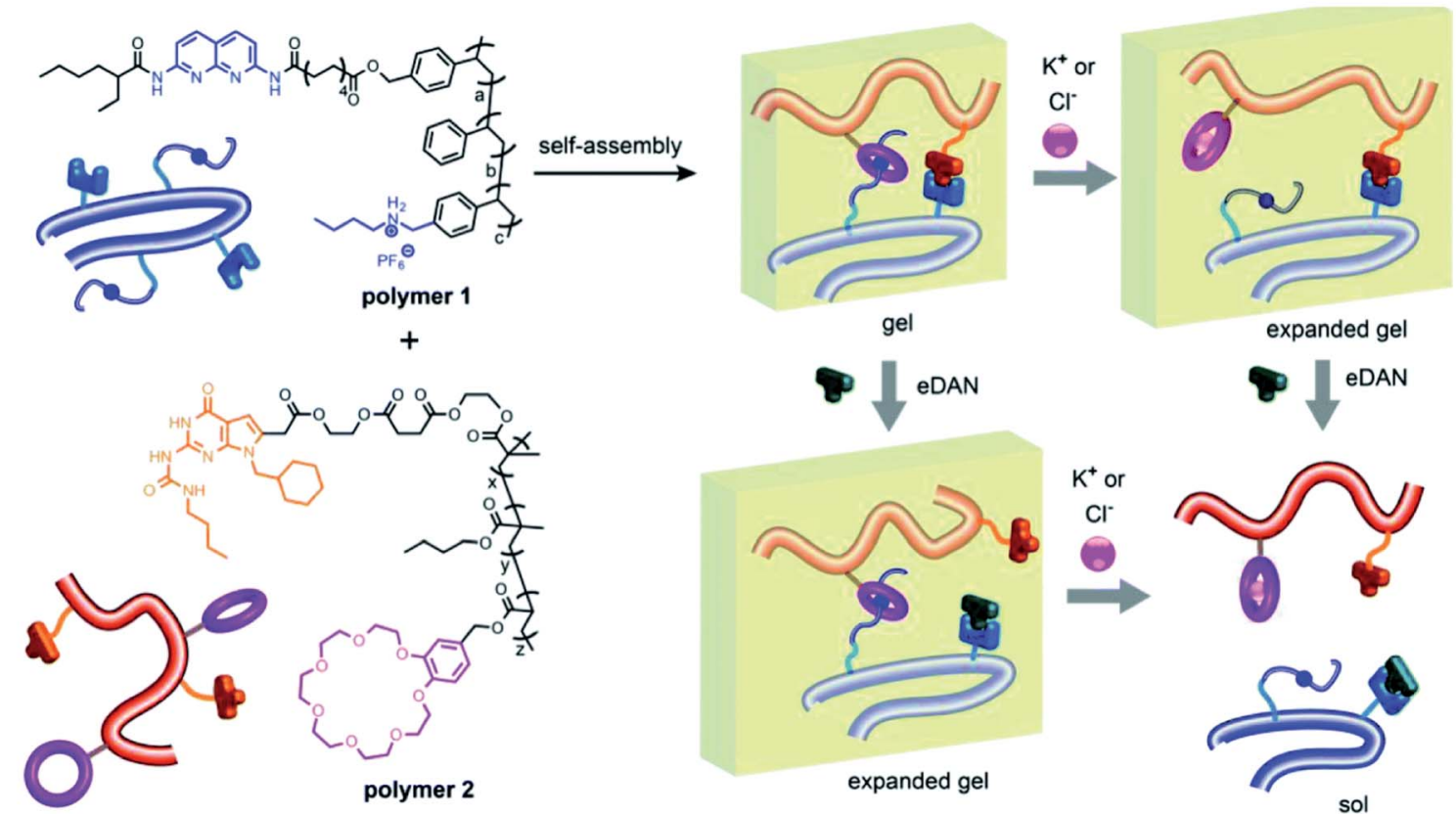

expanded gel
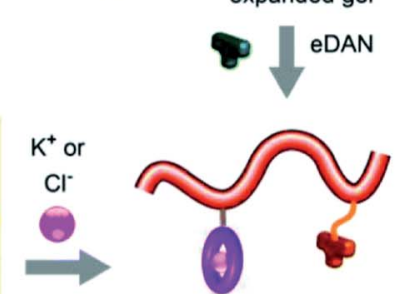

b)
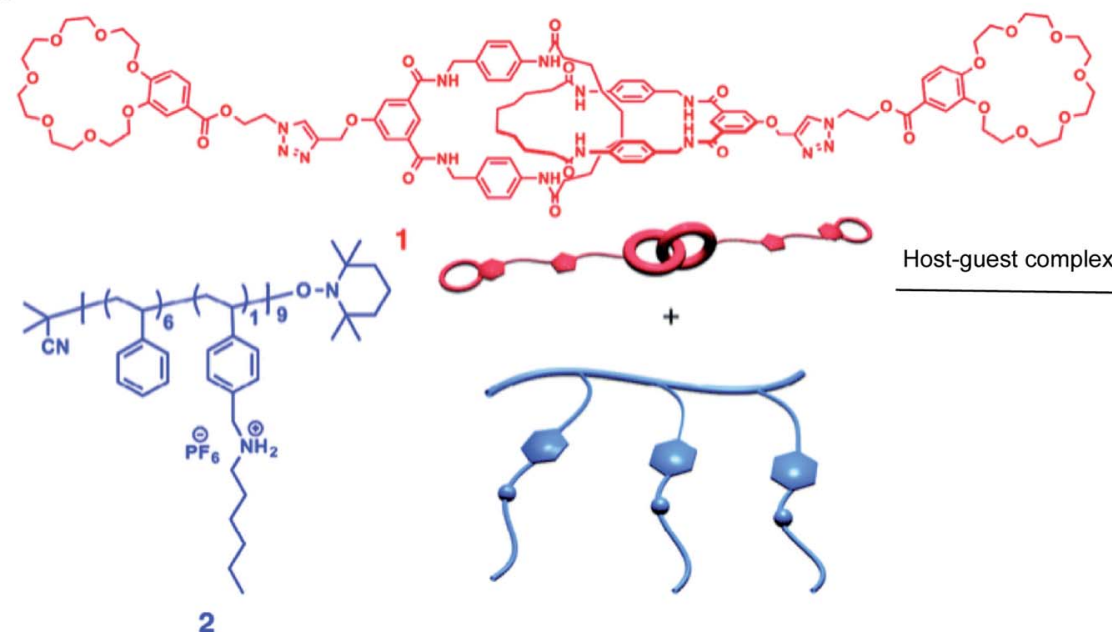

Host-guest complexation

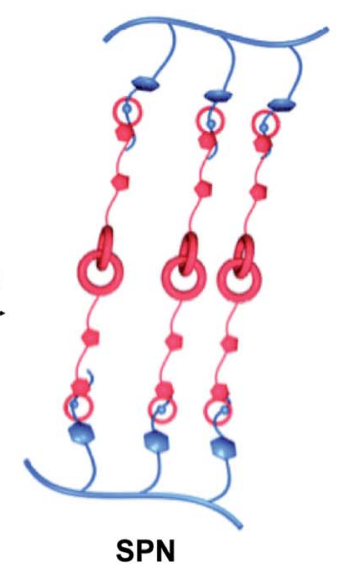

Fig. 2 (a) Illustration of the advantage of the host-guest interaction for double supramolecular cross-linked polymer gels. ${ }^{58}$ (b) Cartoon representations and chemical structures of supramolecular mechanically interlocked crosslinker 1, polymer 2, and supramolecular polymer network SPN $1 .^{60}$ Reproduced with permission from Royal Society of Chemistry, Copyright 2015 and Copyright 2018.

components, and pharmaceuticals. ${ }^{69}$ Also, Dai and co-workers reported the formation of porous hyper-cross-linked $\beta$-CD polymers, which exhibited excellent absorption performance towards small aromatic molecules from water. ${ }^{70}$ Uemasu et al. reported inclusion complexes of well soluble branched $\alpha$-CD with ethyl benzene and xylene isomers in aqueous solution with an order of inclusion selectivity as $p$-xylene $>$ ethyl benzene $>m$ xylene $>o$-xylene..$^{71}$ Yang et al. reported the separation of $p$ xylene from $m$-xylene by selective extraction using an aqueous solution of a bigger size CD derivative. ${ }^{72}$ Extensive studies based on the difference in the CD size, relative alkalinity and dipole moment show a higher selectivity for complexation between $p$ xylene and the bigger size $\mathrm{CD}$ derivative. Under optimal separation conditions, they found that a $1: 1$ mixture of $m$-xylene and $p$-xylene could be concentrated up to $59.71 \mathrm{wt} \%$ with respect to $p$-xylene after a single extraction cycle and up to 81.48 wt $\%$ after four extractions. Although CDs have demonstrated the ability for separating xylene isomers, the relatively low binding affinity of CDs and aromatic hydrocarbons $\left(<10^{3} \mathrm{M}^{-1}\right)$ greatly limited the high selectivity of this method. ${ }^{73}$

CDs have also been effectively utilized for hydrocarbon separation, chiral separation and $\mathrm{CO}_{2}$ capture. Zhang et al. utilized $\gamma$-CD to fabricate covalent organic frameworks (COFs) suitable for $\mathrm{CO}_{2}$ capture. ${ }^{74}$ The ionic nature and microporosity of $\gamma$-CD-COFs facilitate $\mathrm{CO}_{2}$ capture without consuming high energy during the regeneration process. Also, Stoddart and coworkers reported that $\gamma$-CDs which form isostructural extended frameworks in the presence of a wide range of the alkali metal 
salts were utilized as selective absorbents for $\mathrm{CO}_{2}$, due to the permanent porosity and robust crystallinity. ${ }^{75-77} \beta$-CD-based COFs synthesized by reacting heptakis(6-amino-6-deoxy)- $\beta$-CD and terephthalaldehyde at room temperature exhibits selective adsorption of polar micropollutants, such as rhodamine B, $(S)$ naproxen, bisphenol A and 4-nonyl phenol in water due to surface functionalization amino and hydroxyl groups.

\subsection{Calix $[n]$ arenes}

Calix $[n]$ aneres represent the third generation of the family of supramolecular hosts after crown ethers and CDs. Calix $[n]$ aneres are usually made of four to eight arene units, linked by methylene bridges, which can be easily functionalized at both rims, by modifying the methylene groups or the phenol units. However, larger calixarenes, from calix[9]aneres to calix[20] aneres have been synthesized. ${ }^{78}$ The well-defined cavities of these calix $[n]$ aneres with a variable size can sufficiently encapsulate various guests such as anions, cations, or neutral molecules through host-guest interactions. ${ }^{79-81}$ Yamamoto and Shinkai reported the synthesis of calix[4]arene crown ethers with a short oligoethylene glycol chain, providing highly selective recognition for $\mathrm{Na}^{+}$with strong binding affinity compared with $\mathrm{K}^{+}$ions, due to the highly restricted flexibility of the crown portion of this host. ${ }^{82}$

Atwood et al. reported that a hexagonal close-packed arrangement of calix[4]arene forms large unoccupied lattice voids, stabilized by van der Waals forces, as the first calix[4] arene-based supramolecular organic frameworks (SOFs). ${ }^{83}$ The lattice voids of this system were utilized to capture methane at room temperature. However, these voids can also be used to host volatile gases under harsh conditions, including high temperatures and low pressure. Hattori and co-workers studied p-tert-butyl calix[4]arene crystals due to their selectivity for eight different regioisomers of disubstituted benzenes (Fig. 3a). ${ }^{\mathbf{4 4}}$ Four types of inclusion crystals were obtained: $2: 1$ (host :guest) with $p$-isomers and $1: 1$ with $o$-, $m$-, and $p$-isomers. $p$-tertButyl calix[4]arene crystals can selectively separate $p$-xylene from a mixture of xylene isomers, $o$-cresol from a mixture of three isomers of cresol, $m$-dichlorobenzene from a mixture of three isomers of dichlorobenzene and $p$-chlorotoluene from a mixture of three isomers of chlorotoluene. The $p$-tert-butyl calix[4]arene crystals exhibit selectivity for aromatic regioisomers due to their steric bulk and rigidity. These crystals were utilized to absorb hydrochloric acid and iodine which provides a new method to host acidic guests without the requirement for an acid-base reaction. ${ }^{85}$ Ananchenko et al. synthesized a calix[4]arene with longer alkyl chains to balance between the rigidity of calixarene molecules and the flexibility of the long alkyl chains. para-Octanoyl calix[4]arene compared to para-hexanoyl calix[4] arene is more stable up to $183^{\circ} \mathrm{C} .{ }^{86}$ The para-octanoyl calix[4]arene adsorption of linear alkanes $\mathrm{C}_{1}-\mathrm{C}_{4}$, xenon, $\mathrm{N}_{2}, \mathrm{O}_{2}$, and $\mathrm{CO}_{2}$ was measured. Interestingly, paraoctanoyl calix[4]arene exhibits higher adsorption of hydrocarbons, xenon, and $\mathrm{CO}_{2}$ than of $\mathrm{N}_{2}$ and $\mathrm{O}_{2}$, at room temperature. However, the calix[4] arene capacity for $\mathrm{CO}_{2}$ is not as high at low pressure, which suggests the potential of these materials to separate hydrocarbons from $\mathrm{CO}_{2}$. Calix $[n]$ aneres were efficiently utilized in removing toxic water-soluble pollutants from wastewater especially non-biodegradable ones. Shalaeva et al. reported the synthesis of two polymers with amidoamine calix [4]resorcinarene units as sorbents towards three water soluble azo dyes, including acid orange, methyl orange and congo red by hydrogen, electrostatic, dipole-dipole interactions. ${ }^{87}$ The sorption efficiency was explained based on dye-sorbent structure conformity. Lakouraj et al. introduced new polymers with great potential for heavy metal removal, including $\mathrm{Cu}^{2+}, \mathrm{Cr}^{2+}$, $\mathrm{Co}^{2+}, \mathrm{Cd}^{2+}$ and $\mathrm{Pb}^{2+}$ from wastewater by solid-liquid extraction using polytriazolecalixamides (PTCAs) and polytriazolecalixarenes (PTCs), which were prepared by polycondensation and click reactions, respectively (Fig. $3 \mathrm{~b}$ ). ${ }^{88}$ Guo et al. reported the synthesis of a $p$-tert-butyl calix[6]-1,4-crown-4based polymer with high adsorption capacities for different aniline derivatives, reaching $90 \%$, due to the large cavity and stable conformation of calix[6]arene within the polymer backbone, in addition to hydrogen and $\pi-\pi$ stack interactions. ${ }^{89}$ Most recently, polymers with a backbone containing different cavity sizes of calix $[n]$ anere $(n=4,6,8)$ have been tested for herbicide paraquat removal with high uptake capacities reaching $419 \mathrm{mg} \mathrm{g}^{-1} \cdot{ }^{90}$ Several studies developed calixarene-based polymers to capture iodine, due to critical health and ecological effects. ${ }^{\mathbf{9 1 , 9 2}}$ For example, an azo-bridged calix[4]resorcinarenebased porous polymer was studied by $\mathrm{Su}$ et al. for capturing iodine vapor with a high adsorption capacity of $477 \mathrm{wt} \% .^{93}$ Recently, An et al. studied iodine adsorption from water using a series of amino-bridged covalent organic polycalix[4]arenes prepared through the copolymerization between functionalized calix[4] arene with the triazine group and diamines (Fig. 3c). ${ }^{94}$ These polymers exhibit a high iodine uptake up to $310 \mathrm{wt} \%$ by noncovalent interactions, including hydrogen bonding, and anion- $\pi$ interactions between the phenyl rings and triazines groups with iodine molecules. Prata et al. synthesized chiroptical active polymers by copolymerization of calixarene and aryleneethynylene monomers. ${ }^{95}$ These polymers exhibit enantiomeric recognition abilities towards $(R)$ - and $(S)$ - $\alpha$-methyl benzylamine.

\subsection{Pillararenes}

Pillar[ $n]$ arenes are constituted of hydroquinone units linked by methylene bridges at para-positions $(n=5-15)$. Pillar $[n]$ arenes as a new class of synthetic macrocycles have received great attention due to their simple synthesis and functionalization, high solubility in many solvents, their host-guest interactions, and possibility of assembling as supramolecular polymers. ${ }^{\mathbf{9 6 , 9 7}}$ Pillar[ $n]$ arenes have been utilized in the area of separation/ adsorption due to electron-rich and pillar-shaped rigid cavities. Recent review articles have summarized the applications of pillar[ $n]$ arenes in metal ion separation, ${ }^{98}$ and host-guest recognition. ${ }^{99}$ Here we discuss the recent application of pillar $[n]$ arenes in gas and hydrocarbons separation. Tan et al. ${ }^{\mathbf{1 0 0}}$ designed a 3D porous supramolecular organic framework (SOF) from perhydroxyl-pillar[5] arene by intermolecular hydrogen bonds. This pillar[5]arene-based SOF exhibited good thermal 


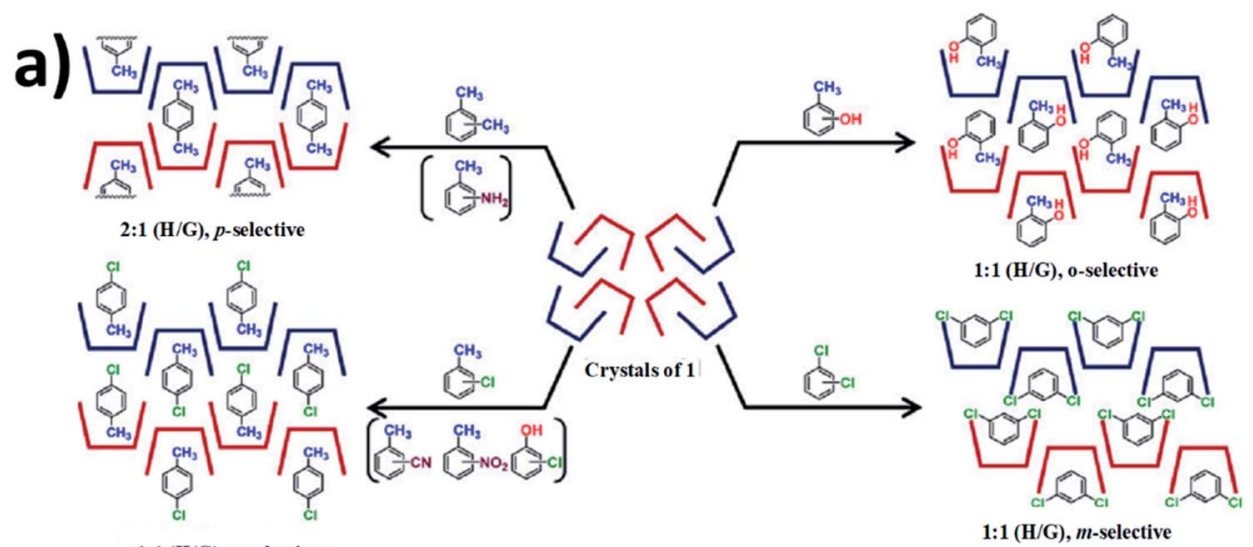

1:1 (H/G), $p$-selective
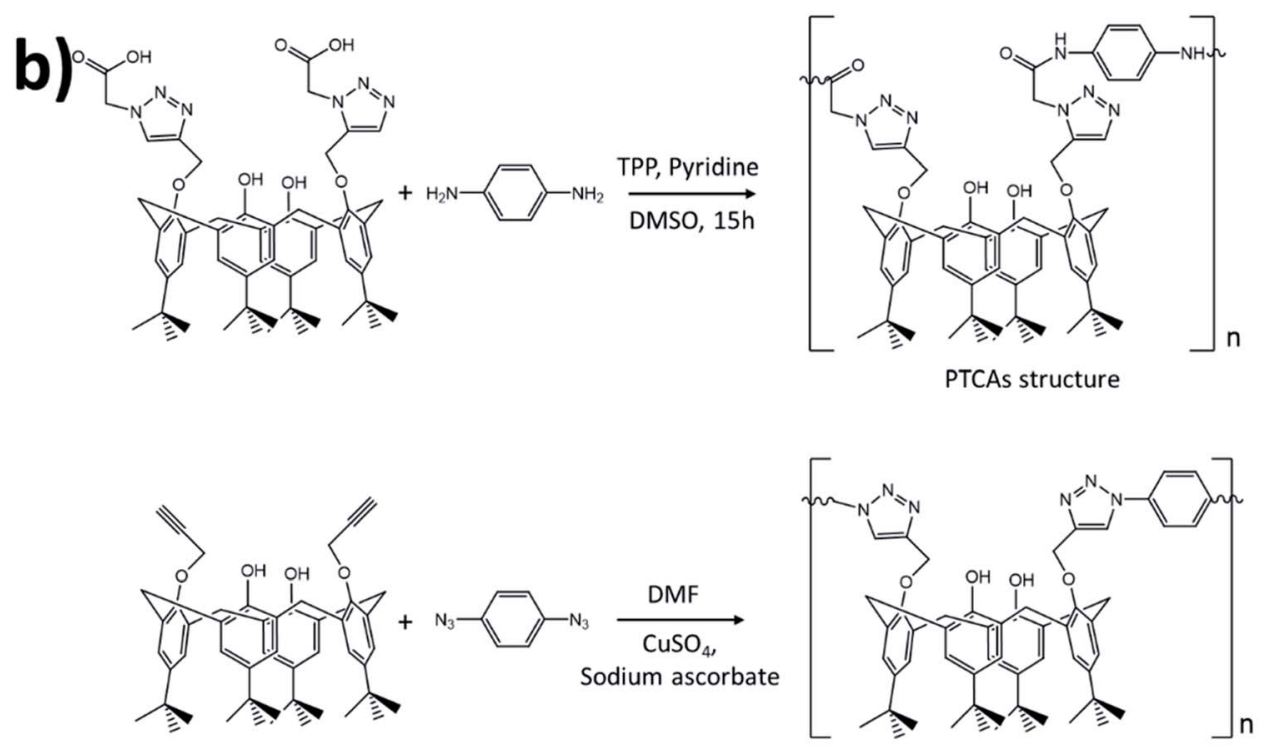

C)
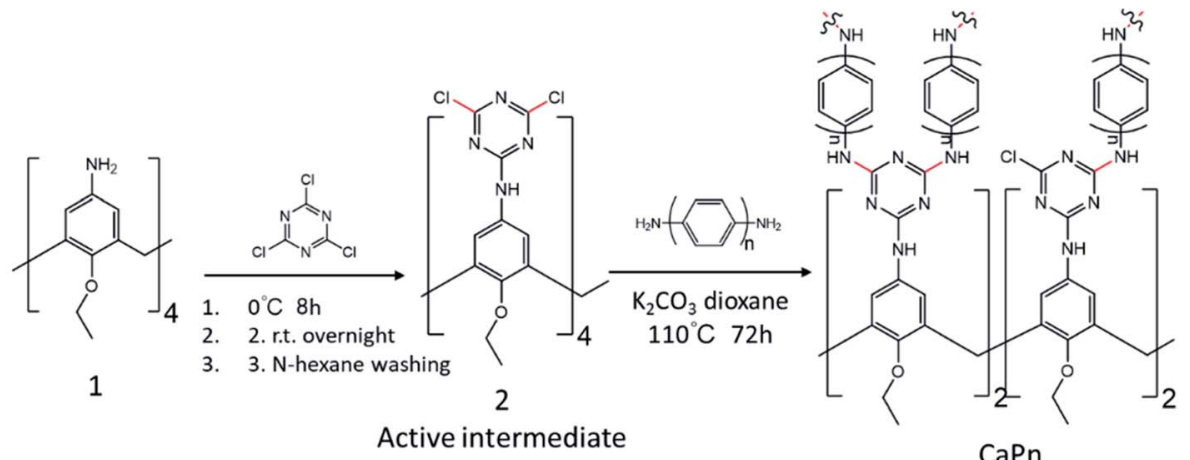

$\mathrm{N}=1,2,3$

Fig. 3 (a) Schematic representation of selective binding by $p$-tert-butyl calix[4]arene. ${ }^{84}$ (b) Preparation of PTCAs and PTC diamines and diazides, respectively. ${ }^{88}$ (c) Synthetic route towards polycalix[4]arenes ${ }^{94}$ Reproduced with permission from American Chemical Society, Copyright 2017, Taylor \& Francis, Copyright 2013, and Elsevier, Copyright 2020.

stability, and permanent porosity and high $\mathrm{CO}_{2}$ adsorption capacity reaching up to $88 \mathrm{mg} \mathrm{g}^{-1}$ under ambient conditions. Later on, two 3D porous SOFs based on pillar[5]arene and pillar [6]arene were synthesized and used for $\mathrm{CO}_{2}$ separation. These SOFs showed remarkable separation properties and high adsorption selectivity for $\mathrm{CO}_{2}$ over $\mathrm{CH}_{4}, \mathrm{C}_{2} \mathrm{H}_{6}, \mathrm{C}_{2} \mathrm{H}_{4}, \mathrm{C}_{2} \mathrm{H}_{2}, \mathrm{~N}_{2}$ and $\mathrm{H}_{2}$ due to pillar $[n]$ arene structural features within these SOFs. ${ }^{101}$ Promising results for environmentally friendly and energy-efficient adsorption and separation processes of hydrocarbons have been reported using pillar $[n]$ arenes. Activated crystals of pillar[5]arene exhibit an uptake of $n$-alkane vapors with chains longer than five carbon atoms. However, the same 
activated crystals did not take up cyclic and branched hydrocarbons vapors, due to the cavity size, which is suitable for host linear alkanes, but not branched or cyclic alkanes (pillar[5] arenes $=4.7 \AA) .{ }^{102}$ The cavity size of the activated pillar[6]arene crystals is $6.7 \AA$, which shows selective uptake for branched and cyclic alkanes such as 2,2-dimethylbutane, 2,3-dimethylbutane, and cyclohexane. ${ }^{103}$ Jie et al. investigated the separation of styrene and ethylbenzene utilizing activated pillar[6]arene crystals. ${ }^{104}$ The separation of these two compounds by conventional distillation is difficult due to the close boiling points. However, styrene with $99 \%$ purity was obtained by exposing activated pillar[6]arene crystals to a $1: 1$ vapor mixture of styrene and ethylbenzene. Subsequently, Jie et al. used pillar[6] arene crystals for para-xylene separation. ${ }^{105}$ The cavity size of pillar[6]arene perfectly fits para-xylene and the $\pi-\pi$ interaction between para-xylene and pillar[6]arene crystals stabilize the host-guest complex, leading to an ideal selectivity for the separation of a 1:1:1 mixture of xylene isomers (Fig. 4a). The same group studied the separation of cyclic aliphatic hydrocarbons such as methylcyclohexane and cyclohexane from the corresponding unreacted aromatic hydrocarbons toluene and benzene with high purity. Adaptive perethylated pillar[5]arene (EtP5) was effectively used to separate toluene from methylcyclohexane with selective uptake driven by $\mathrm{CH}-\pi$ interactions for toluene, reaching $79 \mathrm{~cm}^{3} \mathrm{~g}^{-1}$ at $P / P_{0}=0.5$. Methylcyclohexane was selectively taken up at $P / P_{0}=0.35$ by pillar[6] arene (EtP6) crystals (Fig. 4b). However, perethylated pillar[5] arene and pillar[6]arene crystals did not show the ability to separate cyclohexane and benzene. ${ }^{\mathbf{1 0 6}}$ This unique adaptive behavior of pillar[n]arene crystals encouraged Feihe and coworkers to extend their studies to separate $p$-chlorotoluene from an $o$-chlorotoluene $/ p$-chlorotoluene mixture by perethylated pillar[5] arene and pillar[6]arene crystals with high selectivity towards $p$-chlorotoluene, which was attributed to the appropriate host cavity shape and size. ${ }^{\mathbf{1 0 7}}$ Most recently, they utilized the nonporous adaptive crystal adsorbent strategy to

a)

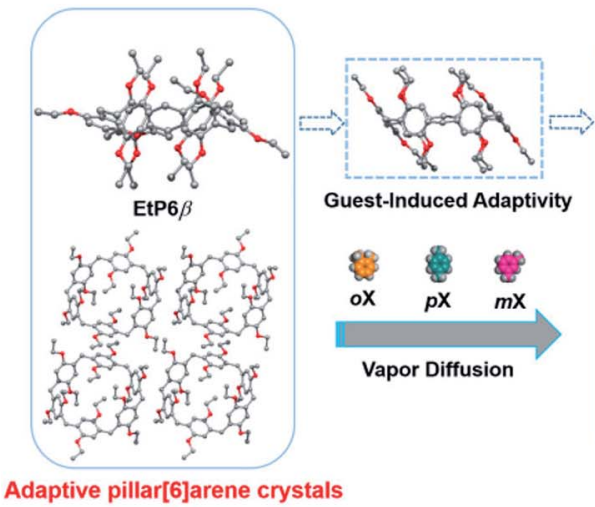

Adaptive pillar[6]arene crystals

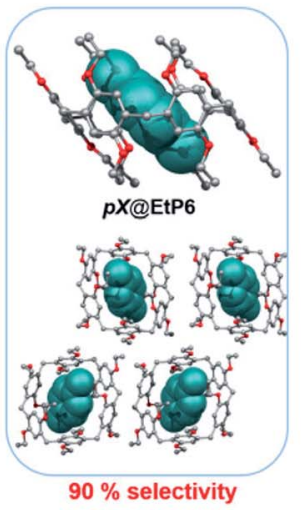

b)
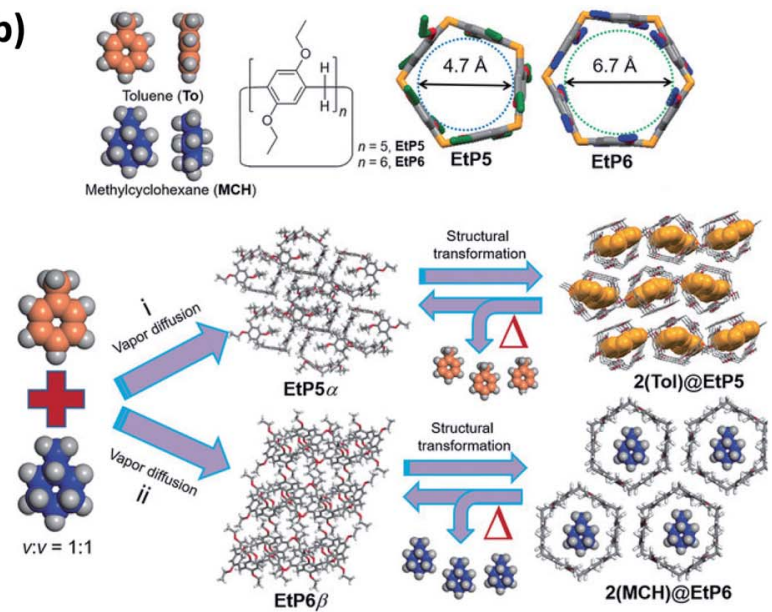

Fig. 4 (a) Schematic representation of xylene isomer separation utilizing perethylated pillar[6]arene (EtP6). ${ }^{105}$ (b) Chemical structures of toluene, methylcyclohexane, perethylated pillar[5]arene (EtP5), pillar[6]arene (EtP6) and schematic representation of the separation processes. ${ }^{106}$ Reproduced with permission from American Chemical Society, Copyright 2018 and Wiley-VCH, Copyright 2018. 
disubstituted isomers was interpreted as a shape-sorting effect, due to the different aspect ratio $(a / b)$ for xylene isomers, as shown in (Fig. 5a). $o$-Xylene has the smallest aspect ratio, which better fits the cucurbit[7]uril cavity. Li et al. investigated the nonporous adaptive crystal behavior for toluene/pyridine separation utilizing cucurbit[6]uril (CB6) (Fig. 5b). ${ }^{115}$ CB6 crystals exhibit remarkable selectivity for pyridine up to $93 \%$ even with the volumetric ratio of pyridine to toluene being 1:100. Moreover, cucurbit[6]uril could be reused without lowering the performance efficiency. Liang et al. reported a new and easy "host-in-host" strategy for organic macrocycle-based frameworks for selective separation of $\mathrm{CO}_{2} / \mathrm{N}_{2} \cdot{ }^{116} \mathrm{CB} 6$ with an appropriate molecular size $(1.44 \mathrm{~nm})$ was encapsulated into the inner mesopores of MIL-101 with a pore size of $1.5 \mathrm{~nm}$ by incipient-wetness impregnation (CB6@MIL-101). CB6@MIL101 showed high $\mathrm{CO}_{2}$ uptake capacity and selective $\mathrm{CO}_{2} / \mathrm{N}_{2}$ separation at low pressures. Furthermore, they report cucurbit [6]uril-based hydrogen-bonded organic frameworks (HOFs) for $\mathrm{SO}_{2} / \mathrm{CO}_{2}$ separation. Cucurbit[6]uril-HOF showed higher $\mathrm{SO}_{2}$ uptake $\left(120 \mathrm{~cm}^{3} \mathrm{~g}^{-1}\right)$ at 0.97 bar and $293 \mathrm{~K}$ compared to $\mathrm{CO}_{2}$, due to the high polarizability of $\mathrm{SO}_{2}$ leading to strong interactions between $\mathrm{SO}_{2}$ and $\mathrm{CB} 6$. This system has an easily scalable synthesis, great structural stability, excellent recyclability and reprocessing. ${ }^{117}$

\subsection{Trianglamines}

Trianglamines are triangular chiral macrocycles synthesized via a condensation reaction between equimolar amounts of chiral 1,2-diamine dicarboxaldehyde. ${ }^{118}$ A series of trianglamine macrocycles have been reported with different functionalities, sizes and geometries. ${ }^{119}$ Trianglamines have been used as chiral shift reagents, and organic catalysts. ${ }^{\mathbf{1 2 0 - 1 2 3}}$ However, the application of trianglamines for separation is still limited.

Khashab and co-workers ${ }^{\mathbf{1 2 4}}$ reported the first trianglaminebased supramolecular organic framework (T-SOF-1) by the full protonation of trianglamine, which directs supramolecular packing. T-SOF-1 showed an excellent affinity for $\mathrm{CO}_{2}$ capture under ambient conditions with the isosteric heat of adsorption around $30 \mathrm{~kJ} \mathrm{~mol}^{-1}$. Furthermore, the possibility of adjusting and improving the selectivity for separation applications by employing host-guest chemistry has been investigated by loading iodine into T-SOF-1. Interestingly, after iodine encapsulation, T-SOF-1 exhibited great capability for $\mathrm{CH}_{4} / \mathrm{CO}_{2}$ separation. Most recently, Khashab's group reported shape selective separation of a biphenyl based trianglimine toward benzene derivatives, where unknown self-assembled structures were discovered as dictated by the nature of the guest molecule (Fig. 6). ${ }^{125}$

\section{Fabrication of macrocycle-based membranes}

Employing a suitable strategy to rationally incorporating macrocycle molecules into membranes is vital to realise their advantages for precise separation. When compared to other common molecules, the rigid molecular skeleton and intrinsic pore structure are the key advantages of macrocycles for membrane applications. Thus, the realization of the full potential of these rigid and intrinsic pore structures is the fundamental objective in the synthesis of macrocycle-based membranes. In the early stages of this field, macrocycles as porous fillers were added to polymeric mixed matrix membranes to obtain recognition sites and extra channels for specific molecules to favorably permeate and recognize. ${ }^{\mathbf{1 2 6 , 1 2 7}}$ a)

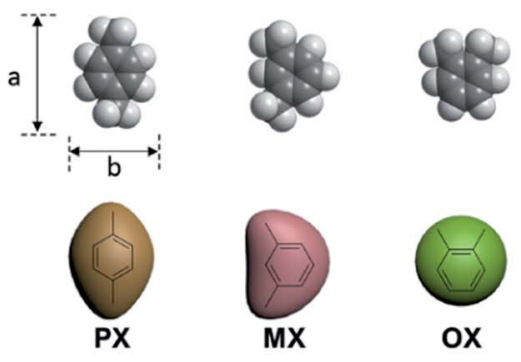

b)
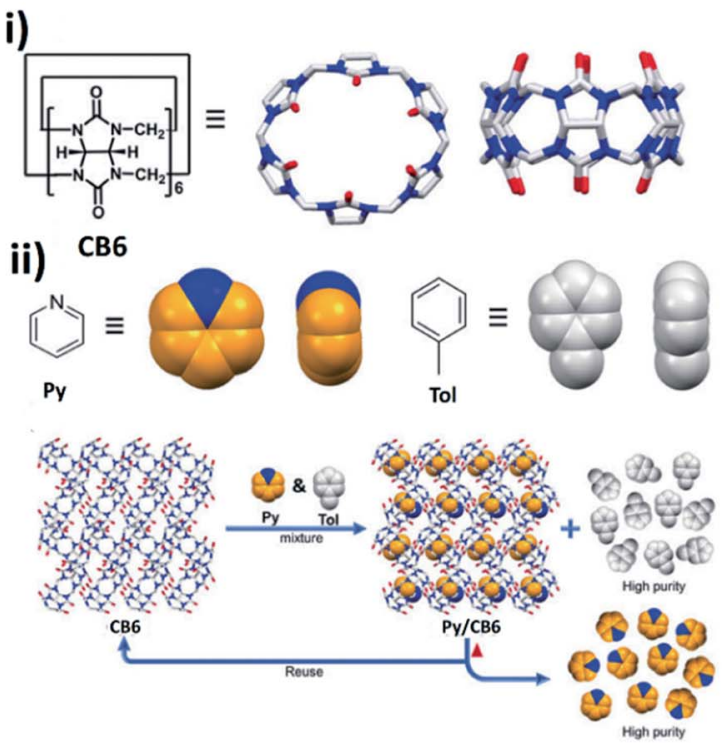

Fig. 5 (a) Schematic representations for the shape-sorting effects of cucurbit[7]uril and xylenes. ${ }^{114}$ (b) (i) Chemical structures and cartoon representations of cucurbit[6]uril. (ii) Schematic of cucurbit[6]uril, as an absorbent for pyridine and toluene separation. ${ }^{115}$ Reproduced with permission from Elsevier, Copyright 2020 and Wiley-VCH, Copyright 2020. 

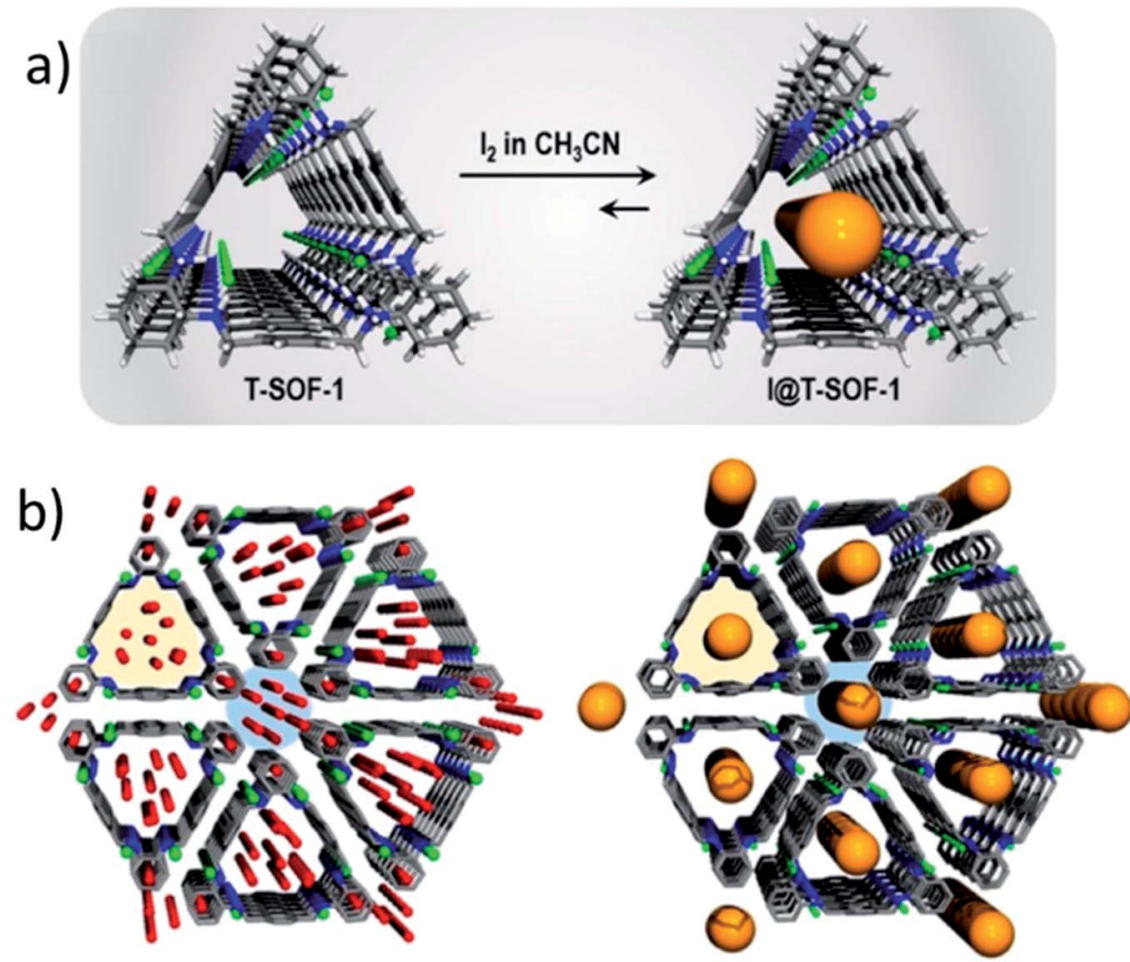

Fig. 6 (a) Preparation of I (aT-SOF-1. (b) Crystal packing along the axis of T-SOF-1 (left) and I@T-SOF-1 (right). Color code: C, gray; H, white; N, blue; O, red; $\mathrm{Cl}$, green and I, orange. ${ }^{124}$ Reproduced with permission from American Chemical Society, Copyright 2018.

However, if the content of the embedded macrocycle molecules is low, the polymeric matrix still plays the major role for the transport and this was evident in early reports. ${ }^{128,129}$ Later stages of development continued to arouse great interest in macrocycles for membrane preparation, using different approaches. For example, membrane surface and pore modification with macrocycle molecules can make the macrocycles molecules to fully interact with guest species, effectively realizing the pore structure potential. However, this method can only introduce a relatively small amount of macrocycle molecules into the membrane. To increase the macrocycle molecule content in the membrane, macrocycle molecules were later used as main building blocks for membrane preparation. By choosing suitable cross-linkers, various kinds of membranes with a high macrocycle content could be prepared. Because of the hypercrosslinked structure, the membranes show high chemical and mechanical stability. By using the host-guest chemistry, stateof-the-art self-assembled macrocycle membranes were prepared. The detailed fabrication processes and strategies are displayed in the following sections.

Competitive polymeric membranes for nanofiltration, reverse osmosis (e.g. ions separations and desalination) and gas separations are frequently manufactured in different steps and can be constituted by different layers. We briefly describe here the general methods or steps of preparation and the opportunities and challenges for macrocycle integration in each of them.

Step 1: the basic layer of a membrane is a porous asymmetric structure that gives mechanical stability to the whole system, without compromising permeance. This step is mostly performed by non-solvent induced phase separation (NIPS). A polymer solution is cast on glass, a metal surface or on a polymeric highly porous non-woven, followed by immersion in a coagulant bath, usually water. Depending on the solution concentration and other preparation conditions, a dense selective layer might be formed leading to an integral asymmetric membrane.

Step 2: the selectivity is however in most cases only achieved by the deposition of an additional thin $(10 \mathrm{~nm}$ to $1 \mu \mathrm{m})$ layer of another polymer or composite material, on the asymmetric layer described in Step 1. This additional layer is obtained by dip-coating ( $300 \mathrm{~nm}$ to $1 \mu \mathrm{m}$ thick) or by interfacial polymerization (IP) (10-400 nm thick). IP is performed by embedding the porous asymmetric support layer in an aqueous solution containing a reactive monomer, typically amino-functionalized and then exposing this system to an organic immiscible phase containing another reactive monomer, typically an acid chloride. The selective layer is formed at the interface.

Step 3: post-modification reactions might be required to tune the hydrophilicity/hydrophobicity balance, reduce pore sizes, add functionalization and enhance stability.

There are opportunities to integrate macrocycles into membranes in all steps, as specified below.

\subsection{Blending}

The integration of macrocycle molecules as non-reactive additives into polymer matrices in Step 1 of preparation of the 
asymmetric porous structure by NIPS, or dip-coating and IP (Step 2) is the simplest and the most straightforward method to fabricate macrocycle-based hybrid membranes. When adding to the coating layers, the total amount of macrocycle needed is of course lower. Compared to purely inorganic fillers, the organic molecular structure facilitates the compatibility of the macrocycles with the polymer matrices. Moreover, the intrinsic pore structures of macrocycles offer recognition sites and an additional free volume for gas, water, and organic solvent molecules to pass through, improving membrane permeability. The recognition capability has the potential of enhancing the selectivity.

In the NIPS method, macrocycles are directly added to the polymer doped solution and homogenized. Then the membrane is formed following a regular NIPS procedure. Macrocycles are randomly distributed over the final membrane structure. The macrocycle is practically held in the polymer matrix by the entangled polymer chains. Because of their functionality, relatively good compatibility with the polymer matrix, and easy dispersion, macrocycles are becoming attractive fillers for membranes.

In many cases, blending is first tested in a dense film, prepared just by solution casting, followed by solvent evaporation, as a pre-evaluation to later prepare NIPS integral membranes or later apply as dip-coatings. In this manner, macrocycles have been incorporated into different polymer matrices, including polyimide (PI, e.g., Matrimid), polysulfone (PSU), cellulose acetate, poly(ether- $b$-amide) (Pebax), etc. One of the pioneering macrocycle-based membranes incorporated $\beta$ CD into a poly(vinyl alcohol) (PVA) matrix for xylene isomer separation by pervaporation. ${ }^{\mathbf{1 3 0}}$ A separation factor of 2.96 for $p$ xylene $/ m$-xylene with a permeation flux of $95 \mathrm{~g} \mathrm{~m}^{-2} \mathrm{~h}^{-1}$ was achieved. This performance was superior to that of a plain PVA membrane, which was attributed to the preferential inclusion of $p$-xylene in the cavity.

The main drawbacks of the blending approach are the risk of diluting the potential added value of the macrocycle if the concentration is low, and the fact that the macrocycle, not being covalently bonded to the matrix, could be potentially leached out during operation, resulting in compromised separation performance. The functionalization of macrocycles with appropriate reactive groups that can covalently bond to the polymer chain is helpful to increase their stability in membranes. Because amine groups can react with the imide structure on the polyimide backbone, CD was modified with ethylenediamine and then was used as a filler for Matrimid/CD composite membrane preparation. ${ }^{\mathbf{1 3 1}}$ The membrane showed superior properties for water/isopropanol separation as well as a good stability. Nonetheless, the choice of macrocycle functionalization is quite specific for each polymer systems.

Other CD-linked polymers have attracted great interest in fabricating CD-based mixed-matrix membranes, because of their relatively high stability. Zhang et al. imbedded $\beta$-CD polymers with branching chain extension in PVA. ${ }^{\mathbf{1 3 2}}$ The incorporated $\beta$-CD polymer had a molecular recognition function, which selectively facilitated the transport of the xylene isomers. Assisted by host-guest chemistry, supramolecular polymers, such as PDMS-conjugated CD/PEG-based polyrotaxanes, have also been used as additives for mixed-matrix membranes preparation (Fig. 7a). ${ }^{133}$ An interesting feature of this polymer is that it self-assembles into a nanoparticle with core-shell morphologies. When used as a filler, the nanoparticle endowed the membrane with abundant ethylene glycol (EG) units without crystallization, which significantly improved the $\mathrm{CO}_{2}$ permeability of the membrane along with only a slight selectivity decrease for $\mathrm{CO}_{2} / \mathrm{N}_{2}$. This combination of characteristics is believed to be favored by the dynamic structure of the nanoparticle, provided by the polyrotaxanes/PDMS chains with translational and rotational freedom.

When the selective coating is prepared by the IP method, instead of dip-coatings, we have macrocycle-based thin-film nanocomposite (TFN) membranes. The macrocycles are only present in this thin $(<400 \mathrm{~nm})$ layer. Therefore, a relatively small content of macrocycles is needed during the membrane fabrication. Macrocycle TFN membranes were first prepared by Mao et $a .^{134}$ in 2015 (Fig. 7b). In their work, CD derivatives with different cavity sizes and functional groups (sulfonic acid, phenyl and imidazolyl moieties grafted on the CD external surface) were introduced in the polyamide (PA) thin film via interfacial polymerization of trimesoyl chloride (TMC) and polyethylenimine (PEI) monomers on top of a PAN substrate. Within the interfacial polymerization layer, the hydrophobic cavities of CDs offered favorable pathways for nonpolar solvents, whereas the hydrophilic free volume cavities between the $\mathrm{CD}$ and the polymer matrix gave efficient pathways for polar solvents. By varying the functionalization, the interaction between the CD derivative and the PEI matrix can be promoted or minimized, tuning not only the polarity of the path, but also the fraction of free volume (FFV) available for permeation around the CD unities. Therefore, a dual-pathway nanostructure is constructed. Increasing the cavity size of the CD allows larger nonpolar solvents to permeate, meanwhile increasing the solvent flux. For example, the toluene $(0.6 \mathrm{~nm})$ permeance increased from 0.13 to $2.52 \mathrm{~L} \mathrm{~m}^{-2} \mathrm{~h}^{-1} \mathrm{bar}^{-1}$, when the CD cavity size changed from 0.6 to $0.75 \mathrm{~nm}$. Similarly, the polar solvents permeance increased when the free volume between the CD molecules and the PEI matrix increases, by decreasing the PEI-CD interfacial interactions.

Macrocycles can not only be used as fillers but also as modifiers of inorganic nanoparticles. Abou-Elanwar et al. ${ }^{\mathbf{1 3 5}}$ prepared TFN membranes by incorporating $\beta$-cyclodextrinencapsulated magnetite $\left(\beta-\mathrm{CD}-\mathrm{Fe}_{3} \mathrm{O}_{4}\right)$ nanoparticles with a diameter of 7-20 $\mathrm{nm}$ into a PA layer by interfacial polymerization between diethylene triamine (DETA) and trimesoyl chloride (TMC). The compatibility between $\mathrm{Fe}_{2} \mathrm{O}_{3}$ and PA was significantly improved by chemical or physical interactions between the hydroxyl groups of $\mathrm{CD}$ and the polyamide matrix. Because of the magnetic properties of $\mathrm{Fe}_{3} \mathrm{O}_{4}$, the $\beta$-CD- $\mathrm{Fe}_{3} \mathrm{O}_{4}$ nanoparticles in diethylenetriamine (DETA) $/ \beta-\mathrm{CD}-\mathrm{Fe}_{3} \mathrm{O}_{4}$ solution could be conveniently separated by using an external magnetic field and the separated nanoparticles could be reused without any significant additional process.

In addition to $\mathrm{CD}$, other macrocycle molecules have been investigated to synthesize mixed matrix and thin-film 


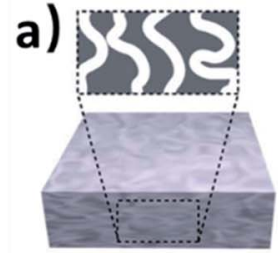

PAN substrate

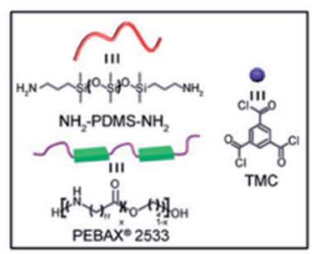

c)

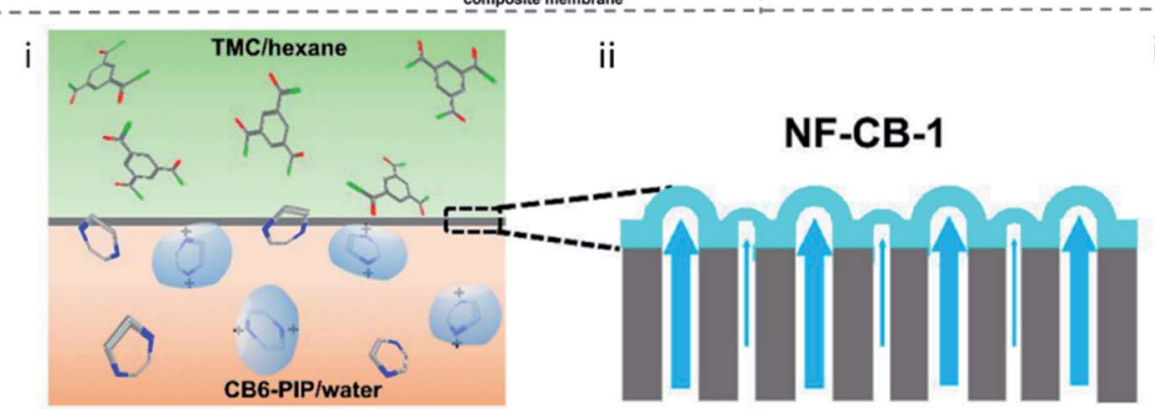

b)
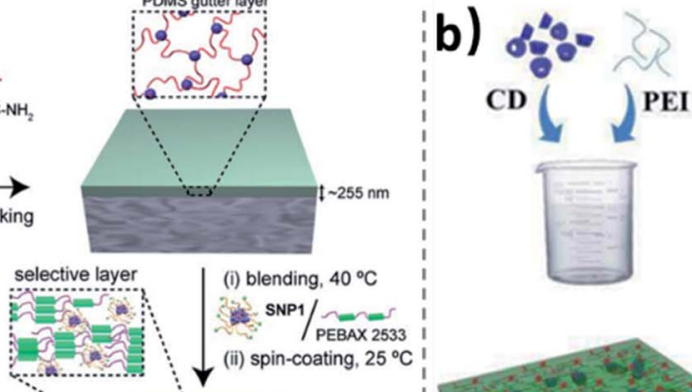

TFN-CD

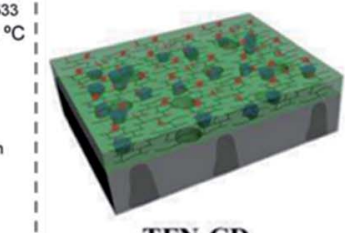

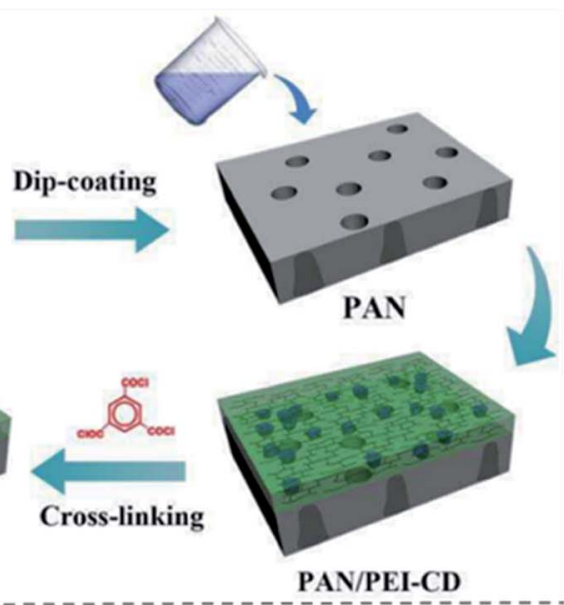

iii

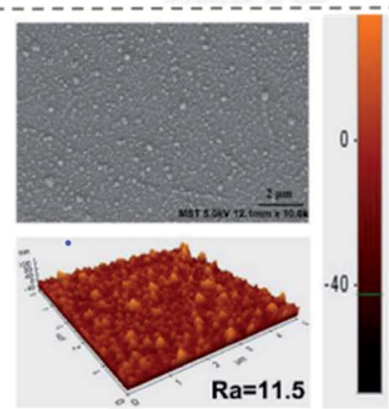

Fig. 7 (a) Schematic illustration towards the fabrication of a TFN membrane with polyrotaxanes/PDMS as additives. ${ }^{133}$ (b) Schematic illustration of the preparation process of the nanocomposite membrane with CD as the additives. ${ }^{134}$ (c) (i) The diffusion of (i) CB6-PIP in the two phase interface, (ii) the sketch of the surface topography of NF-CB-1 membranes, (iii) the SEM and AFM images for a NF-0.1\%CB-1 membrane. ${ }^{136}$ Reproduced with permission from Royal Society of Chemistry, Copyright 2015, American Chemical Society, Copyright 2015, and Wiley-VCH, Copyright 2019.

nanocomposite membranes, due to their special characteristics such as the pore structure and chemical properties. ${ }^{136}$ Using cucurbit[6]uril (CB6)-piperazine (PIP) pseudorotaxane as the aqueous monomer, CB-containing TFN membranes were then prepared by IP (Fig. 7c). The host-guest complex by hydrogen bonding or ion-dipole interactions greatly enhanced the solubility of CB6 in water, making the subsequent interfacial polymerization process feasible. Different from traditional IPmanufactured membranes, this membrane featured two types of permeance paths, including the regular polyamide network free volumes and rotaxane tunnels. Such abundant solvent transport tunnels result in a high reported water permeance of 15.5-25.4 $\mathrm{L} \mathrm{m}^{-2} \mathrm{bar}^{-1} \mathrm{~h}^{-1}$ and a high rejection of $\mathrm{MgSO}_{4}(99.5-$ $92.5 \%$ ), largely surpassing that of conventional polyamide membranes. By using a similar strategy, a type of dendritic macromolecule, PAMAM, was also complexed with CB6 to fabricate a thin-film membrane for high-performance antifouling nanofiltration performance. ${ }^{137}$

For the blending strategy, most macrocycles are used as fillers in the polymer matrix. The presence of the polymer matrix and the relatively low concentration of the macrocycles could, to some extent, compromise the realization of the full potential of macrocycles during the separation process. Hence, utilization of macrocycles in a more efficient manner is highly desirable for membrane applications, as described in the next sub-sections.

\subsection{Surface and pores post modification}

Surface modification has long drawn research attention to impart desired functionalities to membranes. Unlike blending, which alters the physiochemical properties of the bulk polymer matrix, surface modification usually has little or even no effect on the matrix. However, altering the surface composition can be essential to realizing successful applications of membranes that go from water treatment, by remediating fouling, to biomedical devices, by securing biocompatibility. There are mainly two classical methods to perform surface modification: physisorption and chemical reaction. Physisorption is the deposition of species onto the membrane surface physically by electrostatic or van der Waals interactions. The other possibility is the attachment of molecules onto the membrane surface by the formation of covalent or coordinated bonds. Macrocycles have been explored for physical and chemical surface modification of membranes. An early example was the surface modification of commercial cellulose membranes by grafting $\beta$-CD molecules, aiming at racemic amino acid separation. ${ }^{138-140}$ The effects of the spacer arm length, and of the steric groups chosen to modify the $\mathrm{CD}$, on the chiral selectivity have been investigated. It was found that shorter spacer arms and larger steric groups were more favorable. This strategy was further extended to TFN membrane surface modification with CD. ${ }^{141}$

The examples mentioned above are mainly applied to relatively dense layers. Modifications with macrocycles have been 
applied to highly porous membranes, as well. In this case, there is not only a need to modify the surface of the membrane, i.e., the hydrophilic nature, but also the size and properties of the pores. This modification can be achieved by the attachment of specific molecules or polymer segments onto the pore wall. A pioneering fabrication of membranes with pores modified with
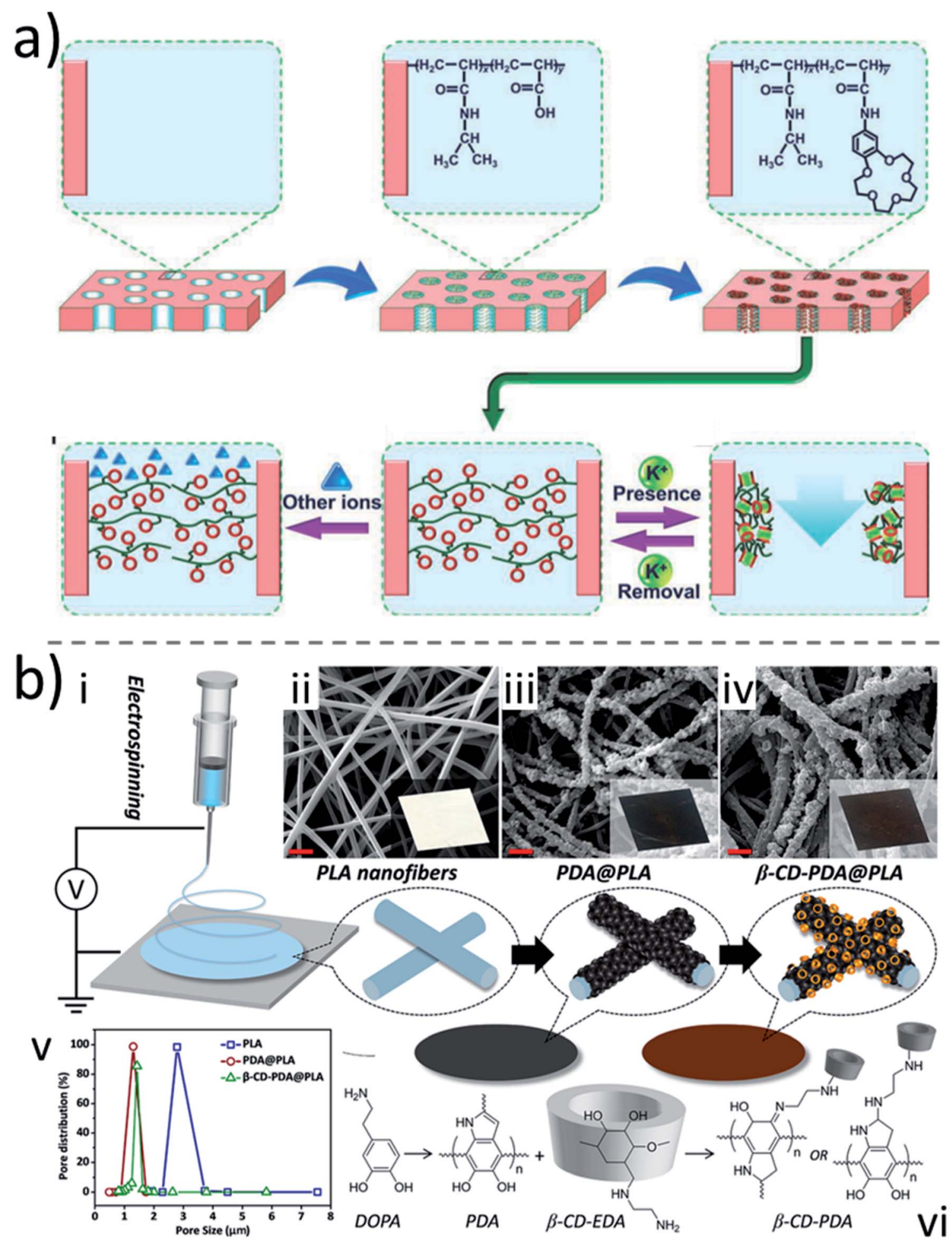

Fig. 8 (a) Schematic illustration of the preparation process and the $\mathrm{K}^{+}$-response of the proposed smart membrane. ${ }^{142}$ (b) (i) Schematic illustration of electrospinning of the $\beta$-CD-PDA@PLA NF membrane, and photographs and SEM images of the (ii) PLA nanofiber membrane, (iii) PDA@PLA nanofiber membrane, and (iv) $\beta$-CD-PDA@PLA nanofiber membrane, the scale bars represent $2 \mu \mathrm{m}$, (v) distribution of the pore size of nanofiber membranes, (vi) graphical synthetic routes of the $\beta$-CD-PDA@PLA nanofiber membrane. ${ }^{144}$ Reproduced with permission from Wiley-VCH, Copyright 2012, and American Chemical Society, Copyright 2018. 
macrocycles was reported in 2012. ${ }^{142}$ In this study, the pore walls of nylon-6 membranes were grafted with a poly $(N$-isopropylacrylamide-co-acryloylamidobenzo-15-crown-5) (poly(NIPAM-co- $\left.\mathrm{AAB}_{15} \mathrm{C}_{5}\right)$ ) copolymer. The crown groups provide a host-guest recognition site for the $\mathrm{K}^{+}$ions (Fig. 8a). The grafted pores function as gates, responsively switching from a "closed" state to "open" state by recognizing $\mathrm{K}^{+}$ions in the environment and vice versa. The $\mathrm{K}^{+}$-responsive gating is rapid, reversible and reproducible. The membrane was highly selective to $\mathrm{K}^{+}$ions. Because of the lack of complexation ability of 15crown-5 with other ions (e.g., $\mathrm{Na}^{+}, \mathrm{Ca}^{2+}$ or $\mathrm{Mg}^{2+}$ ), there is no responsive effect for them. By using a similar strategy, inorganic membrane pore modification with macrocycles was also investigated. ${ }^{\mathbf{1 4 3}}$

This strategy was further extended to nanofiber membranes fabricated by electrospinning. CD molecules were grafted onto polydopamine (PDA)-coated poly(L-lactic acid) (PLA) nanofibers (Fig. 8b). ${ }^{\mathbf{1 4 4}}$ The as-prepared CD-modified PLA nanofiber membranes showed excellent hydrophilicity, underwater oleophobicity, and recyclability, which therefore endowed the membrane with good capability to separate oil-in-water emulsions. As a result, a flux higher than $1500 \mathrm{~L} \mathrm{~m}^{-2} \mathrm{~h}^{-1}$ and $99.5 \%$ selectivity could be reached. The CD-modified PLA nanofiber membranes also demonstrated excellent adsorption (higher than $95 \%$ ) of positively charged water-soluble organic pollutants during the filtration. This is attributed to the hydrophilicity introduced by $\mathrm{CD}$ and its ability of host-guest complexation with organic micropollutants, further elevating the separation potential of the nanofiber membrane for environmental applications.

Besides chemical grafting, physical deposition was also explored for surface modification with macrocycles. Recently, an ion-responsive material was fabricated by spraying benzo-15crown-5 $\left(\mathrm{B}_{15} \mathrm{C}_{5}\right)$ onto a polytetrafluoroethylene (PTFE) membrane. ${ }^{\mathbf{1 4 5}}$ Driven by the unique host-guest chemistry of crown ethers, the wettability of the membrane surface was adjusted based on the complexation between $\mathrm{Na}^{+}$and $\mathrm{B}_{15} \mathrm{C}_{5}$. At a low salt concentration, the membrane surface was highly hydrophobic $\left(\sim 145^{\circ}\right)$ and superoleophilic $\left(0^{\circ}\right)$. Under high salt concentration conditions, the membrane became highly hydrophilic $\left(\sim 20^{\circ}\right)$ and underwater superoleophobic (above $150^{\circ}$ ). These characteristics are convenient for water-in-oil and oil-in-water emulsion separations. The salt-induced wettability transition of the $\mathrm{B}_{15} \mathrm{C}_{5}$-coated membrane results from the polarity variation of the surface. The membrane promoted the salt-responsive demulsification of both water-in-oil and oil-inwater emulsions with outstanding performance and excellent reusability.

Currently, although only CDs and crown ethers are applied in membrane surface (or pores) modification, many more different macrocycles could also be studied due to their unique characteristics, such as the pore size and host-guest complexation ability. Besides influencing the separation properties themselves, CDs have been incorporated as surface modifiers to impart antibacterial/antifouling activity to the membranes. ${ }^{\mathbf{1 4 6 , 1 4 7}}$

\subsection{Crosslinking}

The above-mentioned blending and surface modification approaches typically incorporate relatively small amounts of macrocycle molecules. The potential benefit that could be provided by macrocycles is therefore far from being fully explored. Having macrocycles as the main building blocks for membrane construction is therefore a much more promising strategy. Because of their special porous structure and complexation capability, macrocycles have been widely used to fabricate crosslinked polymers as adsorbents for water treatment. For example, Dichtel and coworkers ${ }^{148}$ coupled the hydroxyl groups of macrocyclic $\beta-\mathrm{CD}$ with tetrafluoroterephthalonitrile to synthesize a mesoporous polymer network for the rapid removal of organic micropollutants. Considering that cellulose-based fibers and $\beta$-CD are similar chemically, they further modified cotton fabrics with a crosslinked CD polymer simply by the same chemistry. ${ }^{149}$ Compared to pristine cotton, the resulting $\mathrm{CD}$-functionalized fabric could rapidly remove organic micropollutants, such as bisphenol A. The functionalized fabric also usefully sequestered volatile organic compounds (VOCs) from the vapor phase more quickly and with a capacity higher than that of untreated cotton as well as other tested commercially available fabric-based adsorbents. The ability to rapidly sequester contaminants could be due to the high surface area, high porosity and the affinity between the cyclodextrin binding sites and the micropollutants. Wooley and co-workers proposed the crosslinking of peraminated $\beta$-CD molecules with pyromellitic dianhydride to form a gel, which could be cast onto a PVDF microfiltration support. ${ }^{150}$ The gel layer thickness was around $20 \mu \mathrm{m}$, and had hierarchical porosity, leading to a high adsorption capability for rhodamine B. High permeances for water $\left(6.5 \mathrm{~L} \mathrm{~m}^{-2} \mathrm{~h}^{-1} \mathrm{bar}^{-1}\right)$ and methanol $\left(8.8 \mathrm{~L} \mathrm{~m}^{-2} \mathrm{~h}^{-1} \mathrm{bar}^{-1}\right)$ were also observed.

The crosslinking examples above were performed in one phase and had more emphasis on adsorption than on the membrane transport application. For membranes, addressing both high selectivity and low transport resistance is essential. Compared to a monophasic reaction, interfacial polymerization can produce much thinner membrane selective layers, which is greatly favorable for high permeance. As far as we know, the first highly crosslinked macrocycle membrane by interfacial polymerization was reported in $2013 .{ }^{151}$ In that case, cyclodextrin was crosslinked with TMC in the presence of triethanolamine. Similarly, in another report, cyclodextrin was crosslinked with TMC on a PVDF support. ${ }^{152}$ Because of the low reactivity of pristine $\mathrm{CD}$ under the membrane preparation conditions, no dense film was generated, leaving the porous morphology unchanged. The formed crosslinked cyclodextrin only improved its hydrophilicity without contributing for selectivity enhancement. The obtained membrane had a higher permeate flux as well as better antifouling properties. But the full potential of CD as a building block could only later be demonstrated.

The breakthrough of crosslinked macrocycle membranes by interfacial polymerization was possible by precise control of reaction conditions (Fig. 9a). ${ }^{\mathbf{1 5 3}} \mathrm{CD}$ was crosslinked with terephtaloyl chloride to form dense selective membranes on a PAN 
a)

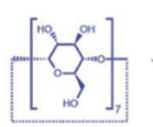

|||

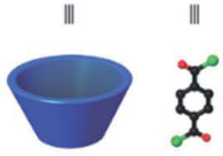

III
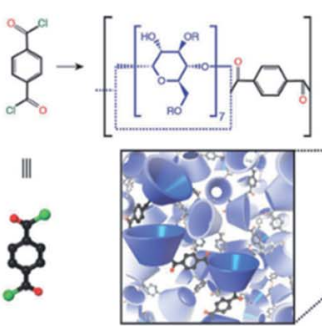

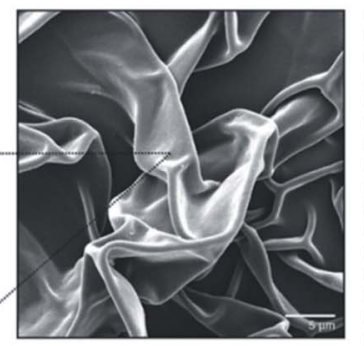

b)
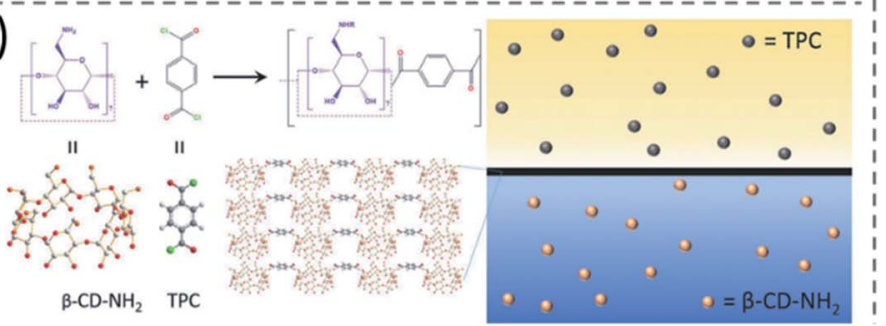

c)
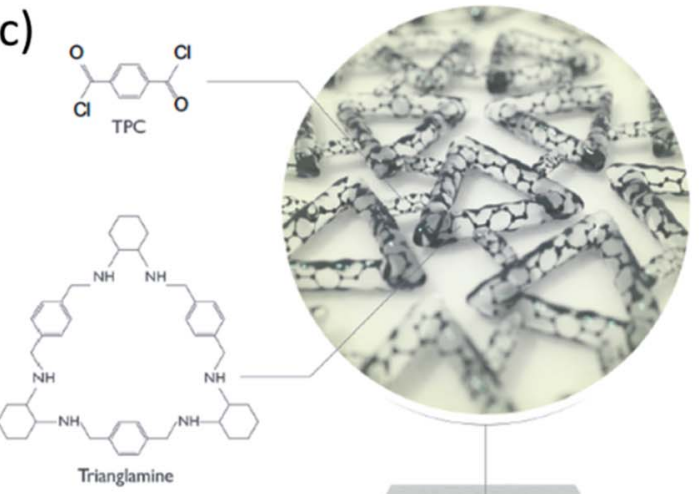

Ultra-thin layer

Membrane

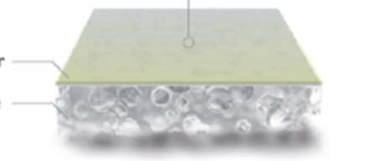

Fig. 9 (a) $\beta-C D$ films made by interfacial polymerization from $\beta-C D .^{153}$ (b) Interfacial polymerization of amino-functionalized CD for TFN membrane formation. ${ }^{154}$ (c) Interfacial polymerization of trianglamine with TPC for membrane formation. ${ }^{156}$ Reproduced with permission from Wiley-VCH, Copyright 2017, Wiley-VCH, Copyright 2020, and Springer Nature, Copyright 2020.

support under exposure of $\mathrm{NaOH}$. With a low $\mathrm{NaOH}$ concentration (0.1-0.8 M), a flat and smooth membrane selective layer was formed, while with a high concentration of $\mathrm{NaOH}(e . g$. 1.0 $\mathrm{M}$ or higher), the formed membrane surface was crumpled. For water and methanol, permeances up to 20 and $9.4 \mathrm{~L} \mathrm{~m}^{-2} \mathrm{~h}^{-1}$ $\mathrm{bar}^{-1}$ were respectively obtained. Interestingly, the high content of crosslinked CD allows the prepared membrane to have the capability to separate small molecules based on their shape. Only molecules with a kinetic diameter smaller than the narrow aperture of the $\beta$-CD cavity $(\approx 0.61 \mathrm{~nm})$ were able to go through it. For example, two neutral molecule dyes with a similar molecular weight, protoporphyrin IX $\left(562.7 \mathrm{~g} \mathrm{~mol}^{-1}, 1.5 \mathrm{~nm}\right)$ and rhodamine B base $\left(442.6 \mathrm{~g} \mathrm{~mol}^{-1}, 0.6 \mathrm{~nm}\right)$ can be sufficiently separated by a $\beta$-CD membrane. In order to improve the reactivity of $\mathrm{CD}$, shorten the membrane preparation time and make the interfacial polymerization of $\mathrm{CD}$ effective enough for industrial application, amino-CD was used for membrane fabrication (Fig. 9b). ${ }^{154}$ Interestingly, the formed membrane is composed of a layered structure of polymerized cyclodextrin. The as-prepared CD crosslinked membrane had good separation performance for organic solvent filtration, out-performing commercial membranes to a large extent, and being comparable or better than recently reported OSN membranes.

In addition to $\mathrm{CD}$, other macrocycles have been explored for crosslinked membrane preparation. For example, two kinds of mesoporous polymer membranes have been prepared from crosslinked sulfonatocalix[4]arenes and pillar[5]arenes with high solvent permeances. ${ }^{155}$ Due to the high permeability and the preferred host-guest interaction between the macrocycles and dyes, both membranes could effectively remove cationic dye molecules via a simple filtration process. Moreover, the captured dye molecules could be easily desorbed from the membranes by organic solvents and the membranes could be recovered to their original states.
More recently, highly crosslinked trianglamine membranes were prepared by interfacial polymerization (Fig. 9c). ${ }^{156}$ The multiple reactive sites of trianglamine led to a highly crosslinked ultrathin selective layer $(<10 \mathrm{~nm})$. Permeances as high as $40 \mathrm{~L} \mathrm{~m}^{-2} \mathrm{~h}^{-1}$ bar $^{-1}$ were demonstrated with a molecular weight cut-off around $450 \mathrm{~g} \mathrm{~mol}^{-1}$. More interesting than size rejection, the membrane was able to separate solutes based on chirality. This was demonstrated with racemic mixtures of a series of amino acids, the best results being for tryptophan, the largest among the tested solutes.

\subsection{Self-assembly}

Unlike the crosslinking strategy that covalently bonds macrocyclic building blocks into a polymer network, another method exploits the self-assembly of macrocycles, linking them via reversible and non-covalent bonds. This soft interaction provides the possibility of forming a more ordered structure during the self-assembly process. Particularly, because of the supramolecular complexation capability of macrocycles to other molecules, host-guest interactions can be used for membrane formation. An intricate example of single-layer 2D ionic organic-inorganic frameworks was reported by Yue et al. ${ }^{157}$ They first built bolaform cationic molecules with two cationic azobenzene groups linked by ethylene glycol segments (Fig. 10a). A complex was promoted with $\alpha$-CD molecules to form a pseudorotaxane. Polyoxametalates as polyanionic clusters acted then as connection nodes between the cationic pseudorotaxanes, forming a single-layer ionic self-assembled framework with $1.4 \mathrm{~nm}$ layer thickness. These soft supramolecular polymer frameworks possessed uniform and adjustable ortho-tetragonal nanopores with their size in the range of 3.4-4.1 nm, with convenient solution processability. Membranes could be obtained by filtration of solutions containing such supramolecular polymer frameworks onto a supporting track-etched 
a) i

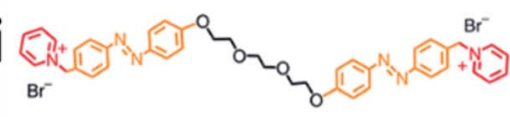

Azo-TrEG.2Br

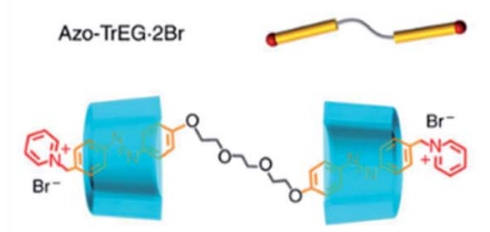

$\alpha-C D$
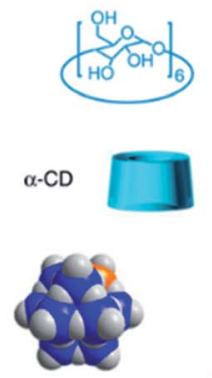

Azo-TrEG@CD.2Br

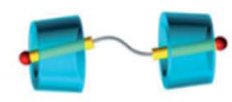

PWV 4-
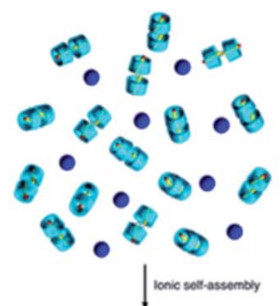

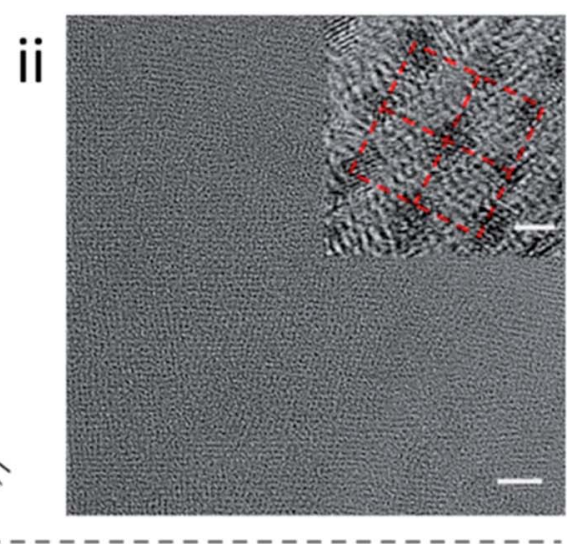

b)
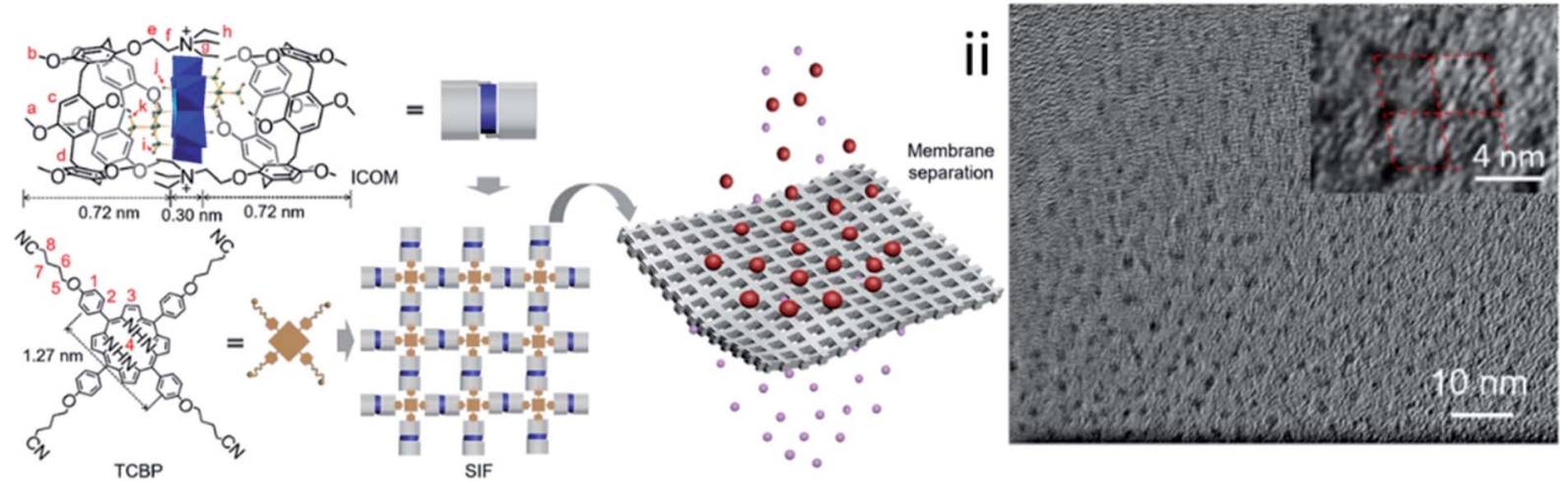

Fig. 10 (a) (i) Schematic representation of the membrane formation mechanism of the CD-based self-assembled framework. (ii) high resolution TEM image of a CD-based self-assembled framework. ${ }^{157}$ (b) (i) Schematic representation of the membrane formation mechanism of the pillararene-based self-assembled framework. (ii) High resolution TEM image of the pillararene-based self-assembled framework. ${ }^{159}$ Reproduced with permission from Springer Nature, Copyright 2016, and American Chemical Society, Copyright 2020.

polycarbonate filter under vacuum pressure. Recently, this group also developed a pillararene-based framework by similar strategies. ${ }^{158,159}$ For example, two positively charged pillararenes interacted with negatively charged polyoxametalate, forming an ionic complex (Fig. 10b). The pillararene on this complex then acted as a supramolecular host unit to further include guest molecules, 5,10,15,20-tetra[4-(4'-cyano)butoxyphenyl] porphyrin bearing four arms in a right angle to each other, forming a $2 \mathrm{D}$ supramolecular-ionic framework. ${ }^{159}$

\subsection{Layer deposition}

Compared to the above host-guest approach, a layer-by-layer (LbL) method is a more common strategy for membrane fabrication due to its simple and adjustable features. A LbL assembly procedure typically involves the deposition in sequence of two materials via attractive forces such as electrostatic interactions, van der Waals, and hydrogen bonding. An important merit of the LbL method is that the membrane thickness can be strictly controlled at the nanometer level by the number of layers. Tieke and co-workers conducted a systematic study on a series of calixarene-containing multilayered membranes via LbL and investigated their metal ion transport selectivity. ${ }^{160-164}$ In their study, sulfonated calixarenes, used as polyanions, were deposited with polycations on a porous support. It was found that the membranes had higher permeability for monovalent ions over divalent and trivalent ones, because of the electrostatic effect. The complex formation between metal ions and the calixarene units also affected the permeance. Calix4 more favorably binds with lithium ions, while calix6 favorably binds magnesium ions, and calix8 transition metal ions. Consequently, for some ions, a high selectivity could be achieved. The LbL membranes prepared from calix8/PVA, ${ }^{161}$ for example, had a separation factor for $\left(\mathrm{NaCl} / \mathrm{LaCl}_{3}\right)$ of $143.3,3$ times higher than that of the control membrane without the macrocycles. ${ }^{162}$

Kazemabad and co-workers reported the first crown-based membrane fabricated via a LbL method. ${ }^{165}$ The crown ether 15crown-5 was first copolymerized with polyethylenimine (PEI), and then was utilized as a polycation in polyelectrolyte multilayer membrane formation via LbL deposition. The manufactured membranes demonstrated $\mathrm{Li} / \mathrm{K}$ selectivity over the duration of $90 \mathrm{~min}$, after which the crown ethers became saturated and the selectivity was lost.

Recently, Shen et al. prepared vesicles constituted by block copolymers with embedded and densely packed pillar[5]arene artificial water channels. ${ }^{166}$ Giant collapsed vesicles were used as $2 \mathrm{D}$ sheets deposited by a modified LbL method on porous supports. The resulting membranes were claimed to have a sharp selectivity profile with a molecular weight cutoff of $\sim 500$ $\mathrm{g} \mathrm{mol}^{-1}$ and permeance of $\sim 65 \mathrm{~L} \mathrm{~m}^{-2} \mathrm{~h}^{-1} \mathrm{bar}^{-1}$, far superior to similarly rated commercial membranes $\left(4-7 \mathrm{~L} \mathrm{~m}^{-2} \mathrm{~h}^{-1} \mathrm{bar}^{-1}\right)$. Since the components of the membranes prepared by the LbL 
method interacted with each other just via electrostatic forces, the macrocycles as small molecules could possibly leach out of the membrane, especially when it comes to liquid separation. Hence, further enhancement of the stability of LbL membranes, for instance by crosslinking is important for their future practical application.

It is well known that surfactant molecules can form different structures due to their amphiphilic characteristic. Macrocycle molecule-based amphiphiles have also been investigated to selfassemble into thin-filma. ${ }^{167}$ Regen and coworkers intensely investigated the gas permeability of surfactant-like calix $[n]$ arene-containing membranes by the Langmuir-Blodgett (LB) method. ${ }^{168-179}$ Such membranes would act like molecular sieves and the presence of the multiple hydrocarbon chain structure in each surfactant would enhance the cohesiveness of these assemblies, thereby minimizing defect formation. In order to improve the stability of the LB membrane, the head of calixarene-based surfactants has been designed with specific groups, such as disulfide moieties for photo-cross-linking, amide oxime groups for hydrogen bonding, quaternary ammonium-based groups for ionic crosslinking. ${ }^{\mathbf{1 6 9 , 1 8 0 - 1 8 3}}$ For example, a homologous series of calix[4]arene-, calix[5] arene-, and calix[6]arenebased surfactants, containing pendant trimethylammonium and $n$-hexadecyl groups have been synthesized and incorporated with poly(4-styrene sulfonate) (PSS) in LB bilayers for He, $\mathrm{N}_{2}$, and $\mathrm{CO}_{2}$ permeability. ${ }^{176}$ As these calix $[n]$ arenes increase in size, their ability to undergo ionic cross-linking increases, the thickness of corresponding glued LB bilayers decreases, and their barrier properties and permeation selectivities increase. For a calix[4]arene/PSS LB bilayer film, the measured permeances of $\mathrm{He}, \mathrm{N}_{2}$, and $\mathrm{CO}_{2}$ were $138 \times 10^{-6}, 2.8 \times 10^{-6}, 162 \times$ $10^{-6} \mathrm{~cm}^{3}\left(\mathrm{~cm}^{2} \mathrm{~s} \mathrm{cmHg}\right)^{-1}$, respectively, while the selectivity of $\mathrm{He} / \mathrm{N}_{2}, \mathrm{He} / \mathrm{CO}_{2}$ and $\mathrm{CO}_{2} / \mathrm{N}_{2}$ was $49,0.85$ and 58 respectively. In contrast, the calix[6]arene/PSS LB bilayer film has $\mathrm{He}, \mathrm{N}_{2}$, and $\mathrm{CO}_{2}$ permeances of $94.1 \times 10^{-6}, 0.59 \times 10^{-6}$, and $51.9 \times 10^{-6}$ $\mathrm{cm}^{3}\left(\mathrm{~cm}^{2} \mathrm{~s} \mathrm{cmHg}\right)^{-1}$ and $\mathrm{He} / \mathrm{N}_{2}, \mathrm{He} / \mathrm{CO}_{2}$ and $\mathrm{CO}_{2} / \mathrm{N}_{2}$ selectivities of 159, 1.8 and 88, respectively. However, all the performances lie below the Robeson upper bound, implying that the space between the calix[ $n]$ arenes, instead of the cavity, is the main permeance passage. Thus, the diffusion through the transitory void seems to have a bigger influence than molecular sieving in the overall permeation process. Achievement of molecular sieving will require further enhancement of the film quality and more tightly packed surfactant assemblies.

\section{Applications of macrocycle-based membranes}

Macrocycle-based membranes can be designed as multifunctional materials for different separation applications. In this section, several typical and emerging applications of macrocycle-based membranes are discussed.

\subsection{Gas separations}

Mixed-matrix membranes constituted of a polymer matrix with dispersed fillers have been long under investigation for gas separation, with the expectation of combining the advantages of both materials. The compatibility between fillers and a polymer matrix is a well-known problem that leads to defects and consequent low selectivity. For example, carbon nanotubes have been functionalized with $\beta$-CD to increase compatibility with a polymer matrix in gas separation membranes. ${ }^{\mathbf{1 8 4 , 1 8 5}}$ While some improvement was achieved, the more promising aspect is the direct use of macrocycle molecules as a membrane filler for gas separation. Noble and coworkers prepared membranes by embedding microporous, solid supramolecular organic materials, such as pillar[5] arene (P5-SOF) into Matrimid-5218 ${ }^{\mathrm{TM}}$, and tested the membranes for gas separation. ${ }^{\mathbf{1 8 6}}$ The membranes offered good $\mathrm{H}_{2} / \mathrm{CH}_{4}$ separation performance $(\alpha=600 \pm 100$; $P\left(\mathrm{CO}_{2}\right)=26 \pm 1$ Barrer) at a filler-loading of $50 \mathrm{wt} \%$, as well as good $\mathrm{CO}_{2} / \mathrm{CH}_{4}$ separation performance $\left(\alpha=180 \pm 40 ; P\left(\mathrm{CO}_{2}\right)=\right.$ $8.5 \pm 0.2$ Barrer). As usual for mixed-matrix membrane materials, the exceptional (light gas/ $\mathrm{CH}_{4}$ ) selectivity is attributed to a combination of increased tortuosity and preferential transport pathways introduced by the pillar[5] arene supramolecular filler. Membranes containing calixarenes as fillers have been also reported for gas separation. ${ }^{187}$ The effect of the introduction of calix[4]arenes and calix[8]arenes with different substituents into a highly permeable polymer matrix of (3-trimethylsilyltricyclononene-7) (PTCNSi1) on gas transport properties was investigated. The selectivity results for $\mathrm{CO}_{2} / \mathrm{N}_{2}$ and $\mathrm{C} 4 / \mathrm{C} 1$ separations were however below the Robeson upper bound. More recently, Pedram and coworkers prepared Pebax membranes containing $p$-tert-butyl-calix[4]arene as an organic additive for $\mathrm{CO}_{2}$ separation. ${ }^{\mathbf{1 8 8}}$ The filler was effectively distributed in the polymeric matrix with high compatibility. The permeability of $\mathrm{CO}_{2}$ was significantly increased by introducing calix[4]arene, as well as the selectivity for $\mathrm{CO}_{2} / \mathrm{N}_{2}$ and $\mathrm{CO}_{2} / \mathrm{CH}_{4}$. The membranes with $0.75 \mathrm{wt} \%$ calix[4]arene had the best results, with the permeation of $\mathrm{CO}_{2}$ increasing from 140.78 to 265.18 Barrer (about 88\% enhancement) in comparison to the pure Pebax-1657 membrane. Accordingly, the selectivity for $\mathrm{CO}_{2} / \mathrm{CH}_{4}$ and $\mathrm{CO}_{2} / \mathrm{N}_{2}$ has been enhanced from 25.35 to 51.51 (almost 103\%) and from 43.18 to 109.16 (almost 152\%) respectively. The high $\mathrm{CO}_{2}$ selectivity was attributed to the interaction of the carbon atom of $\mathrm{CO}_{2}$ with the oxygen atom of the calix[4]arene, as well as its interaction with the benzene ring (Fig. 11a).

Compared with membranes prepared by simply blending macrocycles and polymers, having them uniformly attached and crosslinked to polymer chains might be more advantageous for membranes and more promising for high performance. Liu et al. prepared polymers of intrinsic microporosity (PIM) with $\beta$ CD blended (referred to as PIM-CD) and studied the influence of $\beta$-CD on gas separation performance (Fig. 11b). ${ }^{189}$ Compared with the unmodified PIM membrane, the PIM-CD membranes exhibited a permeability improvement as the $\beta$-CD loading increased. The addition of 2 mol\% $\beta$-CD, significantly enhanced the $\mathrm{CO}_{2}$ permeability from 3368 to 8812 Barrer, an increase of $162 \%$ compared to pristine PIM membranes, without an obvious decrease in gas selectivity. The gas separation performance of PIM-CD membranes surpassed the Robeson upper bound lines for many tested gas pairs $\left(\mathrm{CO}_{2} / \mathrm{CH}_{4}, \mathrm{CO}_{2} / \mathrm{N}_{2}, \mathrm{O}_{2} / \mathrm{N}_{2}\right.$, 
a) i
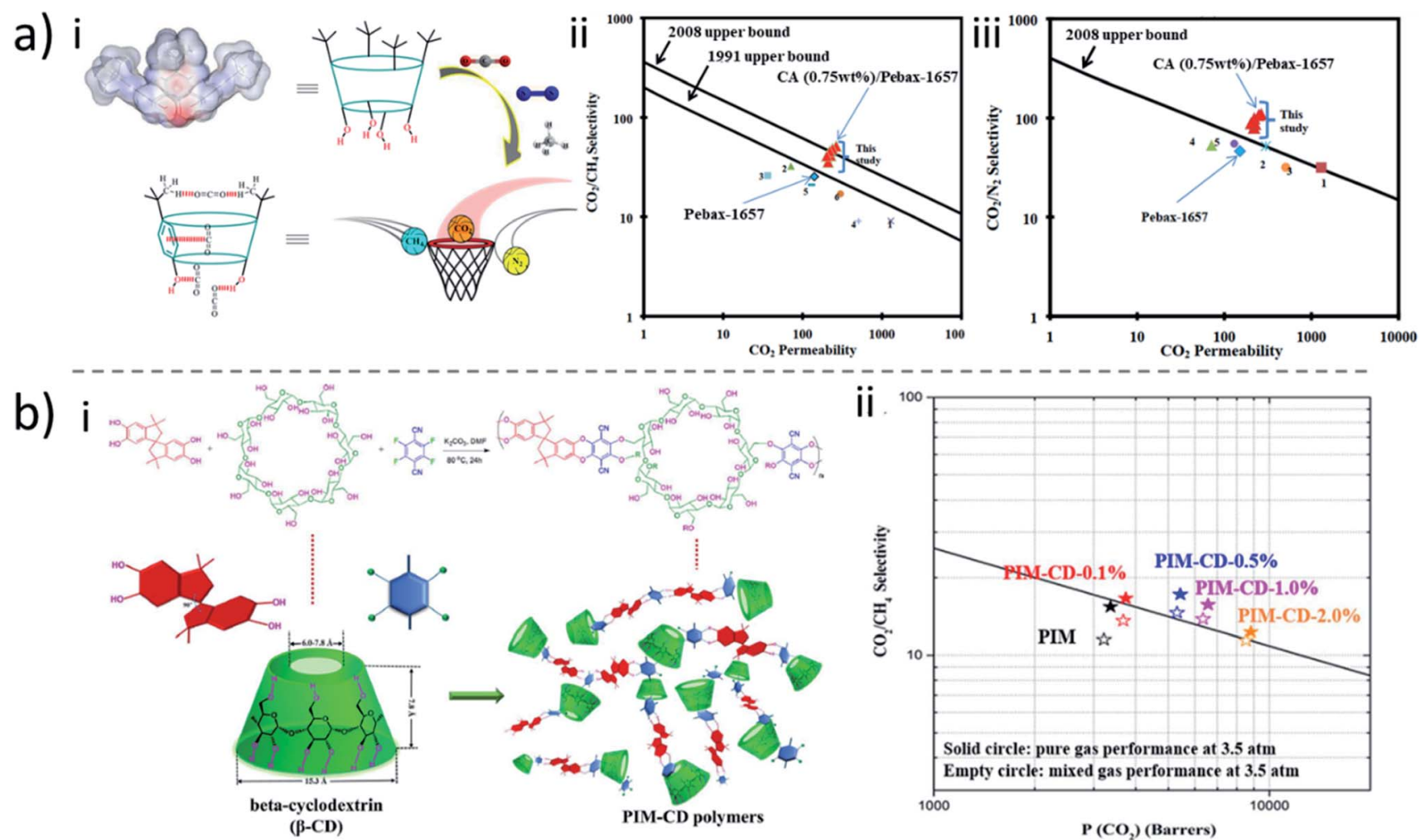

Fig. 11 (a) (i) Possible interactions between calix[4]arene and gas molecules. Comparison of (ii) $\mathrm{CO}_{2} / \mathrm{CH}_{4}$ and (iii) $\mathrm{CO}_{2} / \mathrm{N}_{2}$ separation performances of neat Pebax-1657, and CA/Pebax-1657 MMMs based on the Pebax polymer which are fabricated in this study and the other similar MMMs reported in the literatures. ${ }^{188}$ (b) (i) Crosslinking of PIM and $\beta-C D$ for gas separation membranes. (ii) Mixed gas performance of the PIM and PIM-CD membranes with $\mathrm{CO}_{2} / \mathrm{CH}_{4}(50 \% / 50 \%)$ at $35^{\circ} \mathrm{C} .{ }^{189}$ Reproduced with permission from American Chemical Society, Copyright 2019 and Elsevier, Copyright 2017.

and $\mathrm{H}_{2} / \mathrm{N}_{2}$ ). The PIM-CD membranes showed much better physical aging resistance and can maintain long term stability tests for more than 120 days. This can be attributed to the presence of the $\beta$-CD units, linking the polymer chains by ether bonds and preventing the highly rigid polymer architecture from compacting. Similarly, ether-dibenzo-18-crown-6 and 4tert-butyl-calix[4]arene-based crosslinked copolymer membranes have also been investigated for gas separation. ${ }^{\mathbf{1 9 0 , 1 9 1}}$

\subsection{Liquid separations}

Liquid separations, mainly referring to separations in water and/or organic solvents, has a wide range of membrane applications, such as pollutant removal, desalination, and organic solvent nanofiltration. Compared with gas separation, the main challenge related to macrocycle-based liquid separation is the stability of the membrane, which is exposed to water or organic solvents for a long time. Besides, hydrophilicity/hydrophobicity, surface functionality, the pore size, porosity, and mechanical strength are also important factors that need to be considered in the preparation of advanced membranes for liquid separation. Herein, we summarize the advancement of macrocyclecontaining advanced membranes for application in the following three areas: water treatment, pervaporation, and organic solvent treatment.
4.2.1. Water treatment. The lack of clean and fresh water is a prevailing global issue. Countless people lack access to safe drinking water, and the crisis is becoming more serious due to the increase of population as well as industrial, agricultural and domestic activities. Membrane-based separations can offer practical solutions to harvesting clean water from sea and other sources, mitigating environmental pollution and enabling water reuse by means of ultrafiltration, nanofiltration, RO, or forward osmosis (FO).

One special characteristic of macrocycle molecules is that they can form host-guest complexes with organic molecules with a suitable size or functional groups. Therefore, the presence of macrocycle molecules in adsorber systems can enhance their adsorption capability for organic micropollutants. This is particularly relevant for porous systems constituted of nanofibers for applications rather as adsorbers and less as classical transport membranes. For example, Chen et al. reported the fabrication of a carbonaceous nanofiber functionalized with $\beta$ CD. ${ }^{192}$ The chemically synthesized carbonaceous nanofibers (CNF) were first grafted with $\beta$-CD, and a free-standing CNF membrane could be prepared by a simple filtration process. The membrane shows a remarkable capability to function as an ideal molecular filter through complexation of phenolphthalein molecules with the cyclodextrin molecules grafted on the CNFs. Compared to inorganic analogues, polymer-based fibers are 
even more attractive, being easy to process by a versatile technique such as electrospinning that can be applied to various polymers, polymer blends and composites. Various macrocyclemolecules/polymer blend electrospun nanofiber membranes have been fabricated to filter organic molecules for water treatment. ${ }^{\mathbf{1 4 4 , 1 9 3 - 1 9 5}}$ Teng et al. reported a mesoporous $\mathrm{PVA} / \mathrm{SiO}_{2}$ composite nanofiber membrane functionalized with CD. ${ }^{\mathbf{1 9 6}}$ The composite nanofiber membranes had good performance in the adsorption of indigo carmine dye. The maximum adsorption capacity reached $495 \mathrm{mg} \mathrm{g}^{-1}$ and the adsorption equilibrium was obtained in less than $40 \mathrm{~min}$. Furthermore, the membranes exhibit good recycling properties for practical usage. Zhao et al. reported water-insoluble $\beta$-cyclodextrin-based fibrous membranes prepared by electrospinning and subsequent thermal cross-linking. ${ }^{195}$ Because of the electrostatic attraction, the fibers could favorably adsorb cationic dye like methylene blue. Concerning the selective adsorption, the fiber membrane could separate a methylene blue/methyl orange mixture by dynamic filtration at a high flow rate of $150 \mathrm{~mL} \mathrm{~min}^{-1}$ (Fig. 12a). Celebioglu et al. reported the fabrication of a crosslinked insoluble poly-CD nanofibrous membrane by electrospinning. ${ }^{197}$ Unlike most macrocycle-based nanofibers fabricated as a polymer blend, this electrospinning of CD nanofibers didn't contain any carrier polymeric matrix. Therefore, a high content of $\mathrm{CD}$ in a nanofibrous membrane was achieved. The flexible and free-standing poly-CD nanofibrous membrane had outstanding filtration performance. The removal efficiency for highly concentrated solutions of methylene blue as a pollutant (40 $\mathrm{mg} \mathrm{L}^{-1}$ ) was more than $90 \%$ under a very high flux $(3840 \mathrm{~L}$ $\left.\mathrm{m}^{-2} \mathrm{~h}^{-1}\right)$. Furthermore, poly-CD nanofibers could be re-used after a mild washing procedure with almost the same performance. Besides fibrous membranes, macrocycle-based mixedmatrix and crosslinked macrocycle membranes were also applied for micropollutant adsorption from water. ${ }^{\mathbf{1 4 9 , 1 5 0 , 1 5 5 , 1 9 8 - 2 0 0}}$ For example, macroporous membranes based on blends of polymerized $\beta$-cyclodextrin and PVDF have been recently fabricated. ${ }^{200}$ The filtration adsorption results demonstrated that the optimized polymerized $\beta$-CD membrane almost completely sequestered bisphenol A with a high concentration $\left(50 \mathrm{mg} \mathrm{L}^{-1}\right)$ and high water flux $\left(3000 \mathrm{~L} \mathrm{~m}^{-2} \mathrm{~h}^{-1}\right)$, orders of magnitude higher than that of commercial nanofiltration membranes with similar separation performance. The excellent adsorption capability was due to the synergistic effect of the fast adsorption of the abundant $\beta-C D$, and the large active area provided by the spongy pores.

In addition to adsorber systems, macrocycle-based membranes were also applied in nanofiltration for removing organics from wastewater. ${ }^{\text {201-204 }}$ Macrocycle molecules can offer extra water transport nanochannels and contribute to the high permeance of the membrane. Wang et al. developed a highly permeable thin film nanocomposite nanofiltration membrane containing CD-based polymer nanoparticles integrated in the polyamide separation layer for antibiotic desalination. ${ }^{205}$ The membranes exhibited not only high water permeance $(15.3 \mathrm{~L}$ $\mathrm{m}^{-2} \mathrm{~h}^{-1}$ bar $^{-1}$ ), about three times larger than that of the pristine membrane, but also 97\% erythromycin rejection. Baek et al. reported cucurbit[6]uril-based $2 \mathrm{D}$ polymer films coated onto a support membrane. ${ }^{206}$ The separation selectivity could be simply tuned by changing the surface charge via the modification of the membrane with various spermine derivatives, facilitated by the strong host-guest interaction between cucurbit[6] uril and spermine (Fig. 12b). Besides enhancing the membrane performance, macrocycle molecules have also been helpful in improving the chlorine-resistance and hydrophilicity of the membranes for water treatment. ${ }^{137,141,207,208}$

4.2.2. Pervaporation. Pervaporation is recognized as a highly energy-efficient membrane and shows great promise for liquid separations in refineries and in petrochemical fields as well as in pharmaceutical industries. During a typical pervaporation process, one or more components in the liquid mixture are preferentially absorbed, followed by diffusion across the membrane, and subsequent evaporation at the other side driven by a chemical potential gradient introduced by vacuum or gas purge. The difference in sorption and diffusion for different components is the key to realizing separation. Pervaporation has been mainly applied for dehydration of organic solvents, removal of trace volatile organic compounds from aqueous solution and separation of organic-organic solvent mixtures. Because of their good compatibility and multifunctionality, macrocycles were added to polymeric membranes to selectively enhance or hinder the sorption and diffusion of components during pervaporation. Since CD is highly hydrophilic, its introduction into membranes for pervaporation was mainly focused on alcohol dehydration. ${ }^{131,209}$ Besides, because of the organophilicity of calixarene, calixarenebased membranes have been studied for the removal of organics from water by pervaporation. ${ }^{210}$ On the other hand, the cavity of macrocycles endow them with particular molecule recognition capability, which can be applied in isomer separation by the host-guest interaction using pervaporation.

Jiang et al. added CD in the preparation of Matrimid ${ }^{\circledR}$ pervaporation membranes for dehydration of isopropanol. ${ }^{209} \mathrm{By}$ adding $5 \mathrm{wt} \%$, an increase of $c a .50 \%$ in water flux was observed, without significant change of water concentration in the permeate.

Besides the separation of alcohol/water mixtures, the separation of isomers was also studied. After grafting CD onto the polyamide-imide membrane surface, the membranes show significantly improved separation performance, compared to the unmodified membranes and those simply prepared from CD/polymer physical blends. ${ }^{211}$ The optimal separation performance was found with the CD-grafted membrane cast from a 22 wt $\%$ doped solution, which exhibited a total butanol flux of $15 \mathrm{~g}$ $\mathrm{m}^{-2} \mathrm{~h}^{-1}$ and a separation factor of 2.03 .

Zhang et al. developed a membrane based on a blend between a branched polymerized CD and PVA for separation of $p$-/ $m$ - and $p$-/o-xylene mixtures. ${ }^{132}$ The CD polymer was synthesized by crosslinking $\beta$-CD with ethylene glycol diglycidyl ether (EGDE). The PVA/polymerized $\beta$-CD membrane had a molecular recognition function, which selectively facilitated the transport of xylene isomers.

So far, only $\mathrm{CD}$ and calixarene have been studied for membrane pervaporation. This suggests that there is an urgent 
a) i
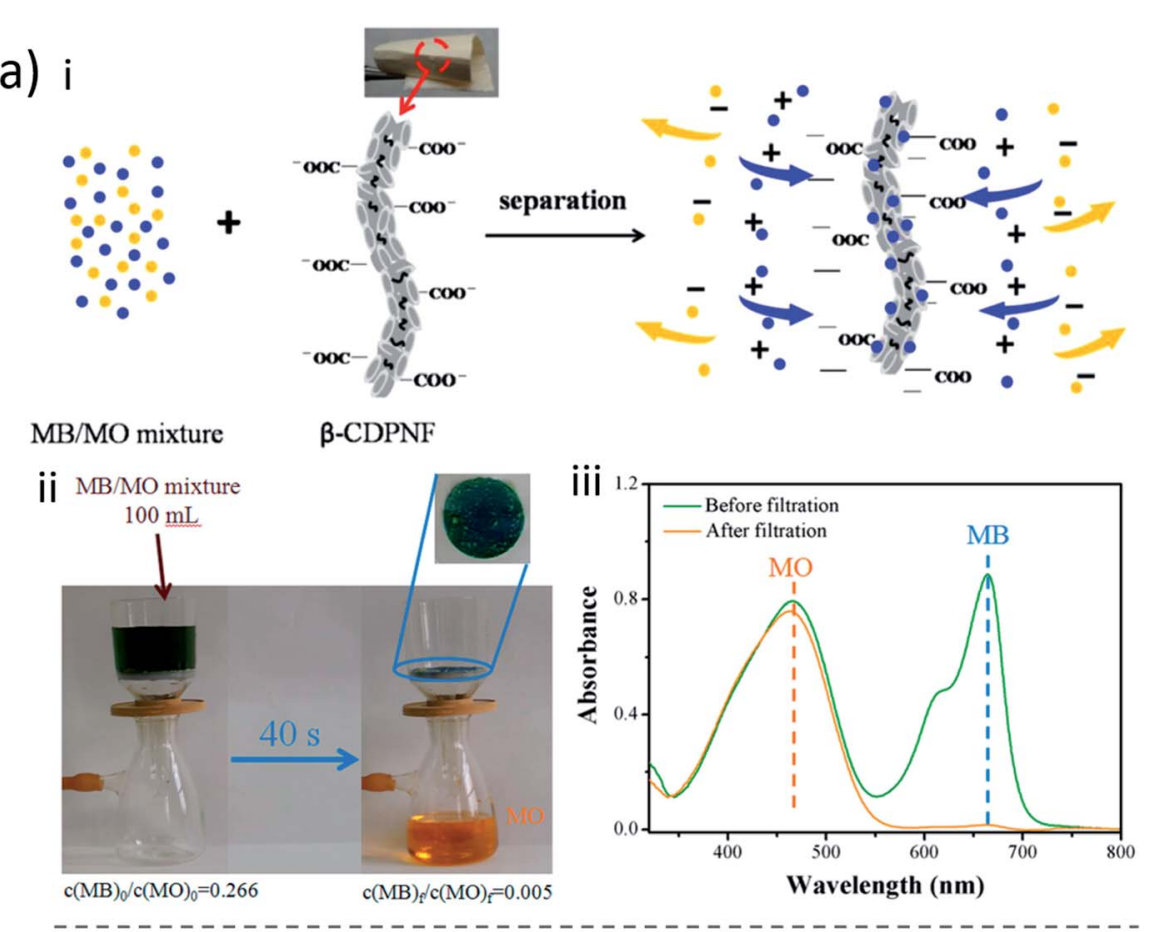

b) i
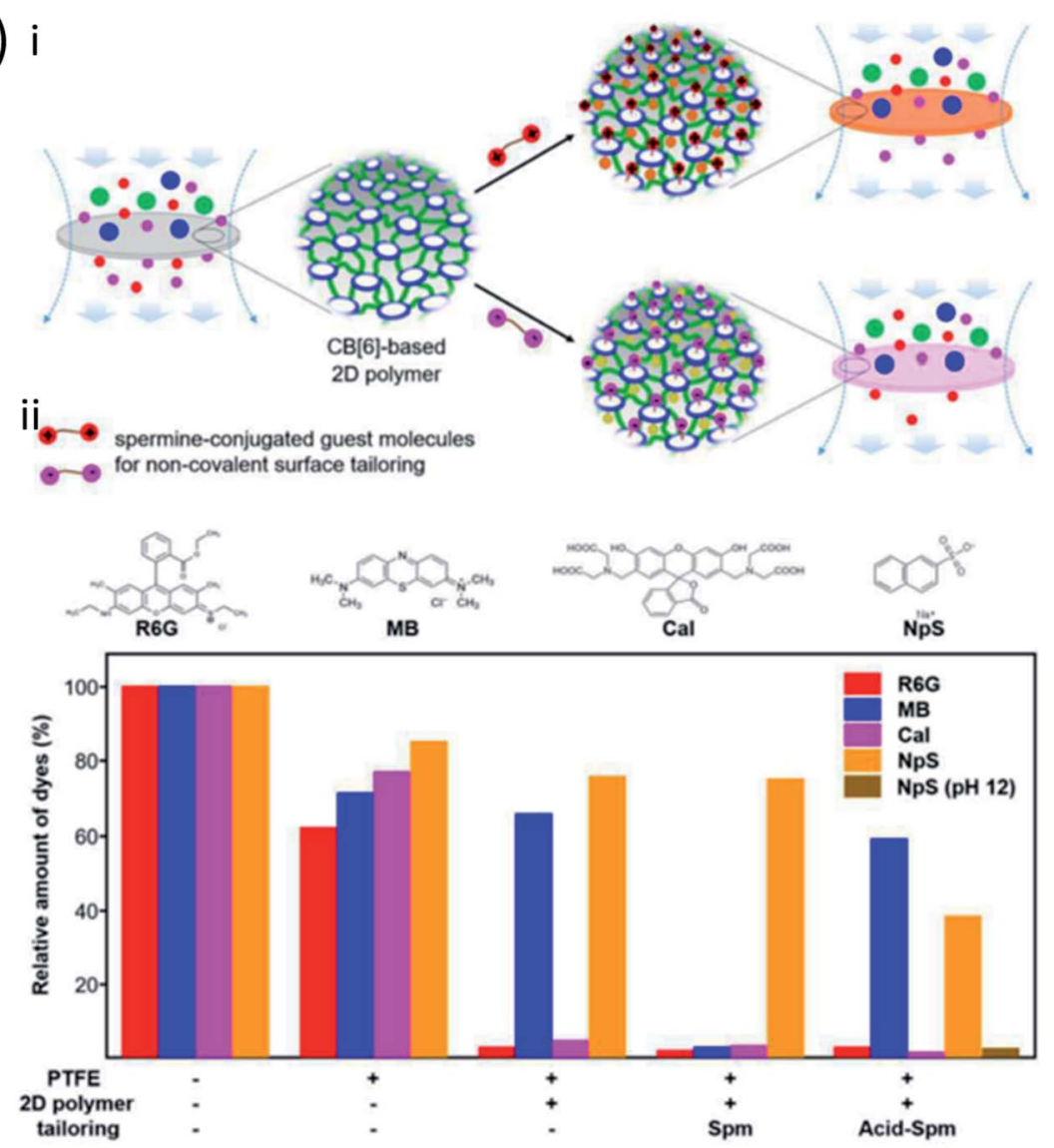

Fig. 12 (a) (i) Separation mechanism of MB/MO mixture dyes by $\beta$-cyclodextrin-based fibrous membranes, (ii) separation of methylene blue (MB) and methyl orange (MO), (iii) UV-vis spectra of MB/MO solution before and after filtration. Reproduced with permission. ${ }^{195}$ (b) (i) Non-covalent surface tailoring of permselective membranes through host-guest chemistry of CB[6], (ii) separation performance for various dyes. ${ }^{206}$ Reproduced with permission from American Chemical Society, Copyright 2015, and Royal Society of Chemistry, Copyright 2016. 
need for much more study on other macrocycle-based membranes in this field.

4.2.3. Organic solvent treatment. Organic solvent treatment is the most common process in the pharmaceutical, petrochemical and refinery industries. A sustainable and energy-efficient method to treat waste organic solvents rather than incinerating is highly needed for sustainability purpose. Traditional separation processes depend on phase change techniques such as distillation and evaporation, which result in huge energy consumption, large footprints, and environmental impact. The use of membrane separations to treat waste organic solvents has apparent merits. Among the favored processes, organic solvent nanofiltration (OSN) is widely studied. The first macrocycle-based membrane for OSN was reported by Mao et $a{ }^{134}$ They embedded CDs into hydrophilic polymeric membranes. The authors confirmed that the cavity size of $\mathrm{CD}$ can affect apolar solvent permeation. Increasing the cavity size of CD allows larger nonpolar solvents to permeate, meanwhile increasing the solvent flux. However, due to the low CD loading, low permeability is obtained, particularly for nonpolar solvents.
In order to increase the role of CDin membrane separation, a high CD content in the membrane is demanded. Peinemann and coworkers prepared crosslinked CD membranes by interfacial polymerization, from which a high CD content membrane has been obtained. ${ }^{153}$ The membrane demonstrated high permeance for both polar and nonpolar solvents. This property was derived from the unique chemistry of CD. The cavity favors nonpolar solvents and the outer surface favors polar solvents. Due to the rigid structure of $\mathrm{CD}$, the cavity acts as an intrinsic pore that can discriminate molecules based on not only their molecular size, but also shape (Fig. 13a). Similarly, amino-CD was also used to fabricate crosslinked CD membranes and membranes by the IP method. ${ }^{154}$ Because of the ultrathin selective layer, a high permeance of solvents was observed. For water, the permeance was about $26 \mathrm{~L} \mathrm{~m}^{-2} \mathrm{~h}^{-1}$ bar $^{-1}$, and hexane about $16 \mathrm{~L} \mathrm{~m}^{-2} \mathrm{~h}^{-1}$ bar $^{-1}$. This membrane also demonstrated shape selectivity. For molecule mixtures (methylene blue vs. safranine $\mathrm{O}$ ), which have the same charge and similar molecular weights but a different molecular shape,

a)
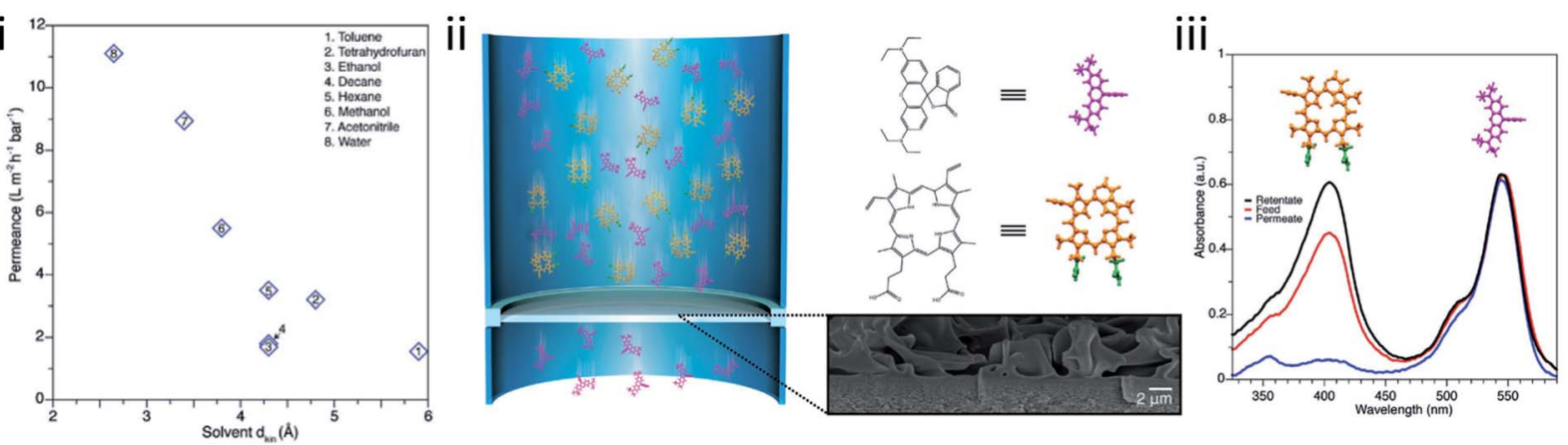

b)
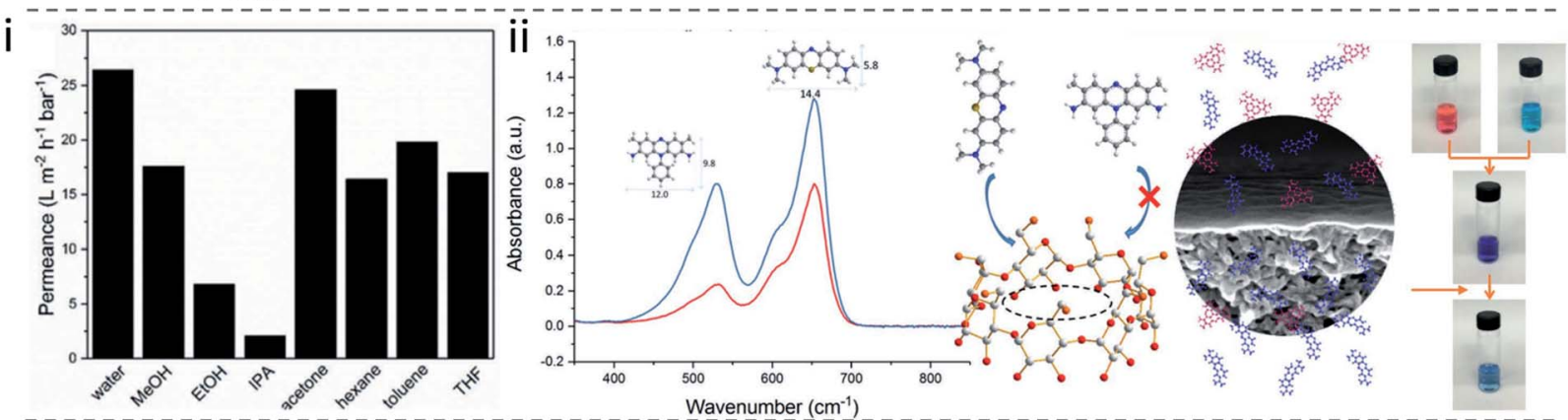

c)
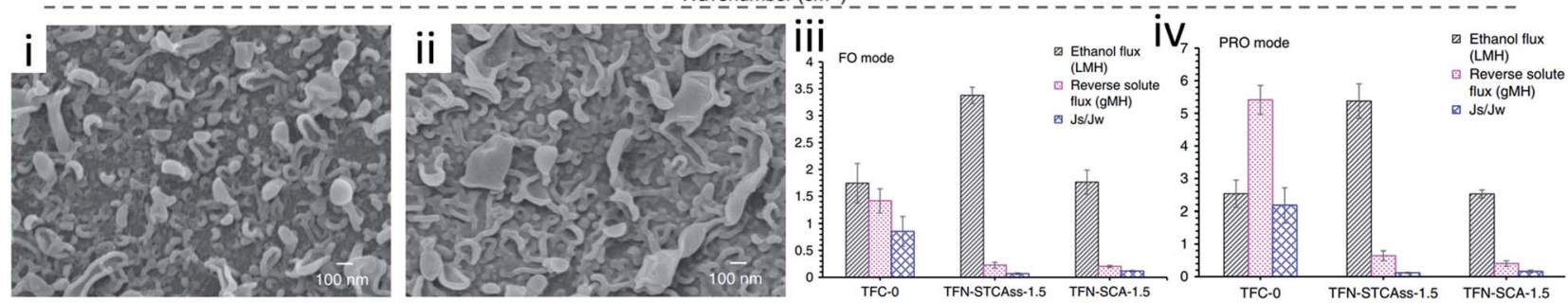

Fig. 13 (a) (i) Pure solvent permeances for eight solvents through the $\beta$-CD membrane, (ii) schematic showing how a $\beta$-CD membrane separates molecules based on their shape, (iii) UV-vis absorption spectra of a methanol solution with PPIX (orange molecule) and RB (pink molecule) to evidence the separation performance of the $\beta-C D$ membrane. ${ }^{153}$ (b) (i) The permeance of various solvents through the polyamide-CD membrane, (ii) UV absorption spectra and photos of the mixed dyes (methylene blue, and safranine O) in methanol solution before (blue) and after (red) permeation through the membrane. ${ }^{154}$ (c) FESEM images of (i) TFN-STCAss-1.5 and (ii) TFN-SCA-1.5, OSFO performance for the (iii) FO mode and (iv) PRO mode. ${ }^{213}$ Reproduced with permission from Wiley-VCH, Copyright 2017, Wiley-VCH, Copyright 2020, and Springer Nature, Copyright 2020. 
much higher rejection was observed for safranine $\mathrm{O}$, because of its bulkier molecular structure (Fig. 13b).

Besides CD-based membranes, a few other macrocycle molecules have been applied to prepare membranes for OSN. ${ }^{136,212}$ For example, Zhai et al. prepared a polyarylate membrane from waterwheel-like macrocycle Noria via interfacial polymerization. ${ }^{212}$ The rejections of the resulting Noria membrane increased with the molecular weights of various dyes, leading to a molecular weight cut-off of $820 \mathrm{~g} \mathrm{~mol}^{-1}$. The resulting membrane had relatively high permeance for polar solvents. However, lower permeance was observed for nonpolar solvents.

In addition to OSN, organic solvent forward osmosis (OSFO) is being considered promising for organic solvent treatment. Compared to OSN, OSFO has lower fouling tendency and can treat highly concentrated feed solutions. Recently, Chung and coworkers designed membranes by ionically blending sulfothiacalix[4]arene (STCAss) and sulfocalix[4]arene (SCA) in the polyamide network obtained by interfacial polymerization, and examined their potential for OSFO (Fig. 13c). ${ }^{213}$ The membrane containing $1.5 \mathrm{wt} \%$ STCAss mixed with phenylene diamine in the aqueous phase during the membrane preparation exhibited higher ethanol fluxes than the pristine IP-manufactured membrane, while the ethanol flux of the membrane containing SCA was not enhanced. This can be explained by the different cavity sizes of STCAss $(5.1 \AA)$ and SCA $(4.2 \AA)$ as compared to the kinetic diameter of ethanol $(\sim 4.4 \AA)$.

\subsection{Chiral separation}

Chiral separation is an important process for the pharmaceutical and chemical industries. Though conventional techniques have long been developed to discriminate enantiomers from racemic mixtures, membrane technology has advantages, such as high-throughput, being energy-saving, pollution-free, lowcost, and easy operation. The introduction of advanced chiral carriers into membranes may achieve high chiral selectivity and efficiency, reducing the number of steps for separation.

Macrocycles can provide a useful platform for chiral separation membranes. However, until now, most studies focused on cyclodextrin-based membranes for chiral separation. It is assumed that due to the chiral environment of cavities, CD offers three-point interactions for the chiral recognition of various organic molecules: hydrophobic interactions and shape fitting in the CD cavity and hydrogen bonds with the hydroxyl groups at the opening of the CD. Chung and coworkers functionalized the surface of commercial cellulose dialysis membranes with $\mathrm{CD}$ and systematically investigated the chiral separation performance. ${ }^{138-140}$ These CD-cellulose membranes showed a dramatic increase of enantioselectivity for racemic LD-tryptophan compared to the pristine cellulose membrane. Interestingly, enantioselectivity was found to increase with decreasing spacer arm length of $\mathrm{CD}$, and the highest selectivity of 1.2 was obtained when a mixture of $\mathrm{CD}$ with various spacer arms was grafted to the membranes. After functionalization of $\mathrm{CD}$ with henzoate groups, the enantioselectivity can be further increased to $1.3-1.5 .^{140}$
Gupta and coworkers prepared membranes by phase inversion, mixing $\beta$-cyclodextrin, glutaraldehyde, and polysulfone to promote post crosslinking. ${ }^{214}$ This membrane demonstrated excellent enantioselectivity for D-phenylalanine, with a permeate enrichment of up to $81 \%$ enantiomer excess.

Recently, Huang et al. prepared thin-film composite membranes using trianglamine as the building block. Compared to levorotary analogs, these membranes clearly rejected dextrorotary molecules more, both in experiments with separated enantiomers and with racemic mixtures. In the case of single chiral enantiomer separation, the rejection of $\mathrm{D}^{-}$ leucine is $32 \%$, while that of L-leucine is only $3 \%$. For racemic separation, the rejection of D-leucine is $31 \%$ compared to the $17 \%$ rejection for L-leucine. ${ }^{156}$

\section{Conclusion and outlook}

Macrocycles are molecular entities displaying a combination of molecular recognition and complexation properties with vital implications for host-guest/supramolecular chemistry. One of the most fascinating features of macrocycles is the presence of intrinsic pores in their molecular structure. Furthermore, the advances of synthetic macrocyclic chemistry endow them with tailored functionalities. All these aspects make macrocycles attractive for membrane design and separations. In this review, we first present an introduction of common macrocycle application for membrane separation based on their chemical compositions, including crown ethers, cyclodextrins, calixarenes, cucurbiturils, and pillararenes. A series of fabrication strategies of macrocycle-mediated membranes in terms of the specific properties of macrocycles, and functionality, have been summarized, including blending, surface modification, crosslinking, self-assembly, and layer deposition. Macrocycle-based membranes with diverse properties such as molecular recognition, molecular sieving, and surface hydrophilicity have been manufactured. These membranes were explored for gas separation, water treatment, organic solvent treatment, pervaporation, and chiral separation, displaying great potential in membrane technology. Particularly, compared to blending and surface modification, self-assembly and interfacial polymerization result in membranes with a high macrocycle content, which is highly favorable for the separation process. Ultrathin macrocycle-based membranes can be fabricated by layer-bylayer stacking, and by interfacial polymerization with extremely high permeability, implying the promise of these methods for the future development of membranes.

Although significant progress has been already achieved during the past few decades, macrocycle-based membranes are still in the infant stage. There are still limitations and challenges to be addressed. Researchers should consider the stability of macrocycles in membranes, especially for those prepared by physical blending and layer deposition strategies due to the lack of covalent bonds. Macrocycles may leach out of the membrane when it comes to liquid separation because of the possible swelling and dissolution. Hence, securing the membrane stability during applications is the precondition for their practical use. We believe that enhanced mechanical and 
chemical stability, higher rejection selectivity, enantioselectivity, permeance, adsorbability and fouling resistance are pre-requisites to extend the applications and guarantee translation into industrial separations. We believe that macrocyclebased membranes will be intensively studied as a new research hotspot of membrane technology for years to come. Specifically, with the rapid development of macrocycle chemistry and materials science, macrocycles with tailored polarity, molecule favorable properties and hydrophilicity/hydrophobicity are also expected to fit the future higher demand for organic solvent nanofiltration, gas separation, and pervaporation. Macrocycles possess intrinsic cavities, and distinct transport and complexation properties, whose influence on the separation performance of membranes is unclear, which should be further pursued.

This review focuses on a handful of common macrocycles. Meanwhile, many other macrocycles like the blue box and oligomeric p-conjugated aromatic diimide-based chiral cyclophanes, which also possess intriguing properties, are attractive candidates for membrane preparation, but the related studies have not been reported yet. Combining membranes with these macrocycles will bring about opportunities to create high-performance membranes, improve their selectivity, and endow them with specific properties. Therefore, further applications of these macrocycle-based membranes need to be investigated and studied. Furthermore, the design and synthesis of novel macrocycles with desired properties guided by first-principles and molecular simulations from the very start of the process of membrane preparation would be highly suggested. A detailed understanding of the macrocycle structure and properties will greatly assist in the rational design and synthesis of macrocycle-based membranes.

Finally, benefiting from the unique supramolecular hostguest properties of macrocycles, introducing guests with specific properties to the membrane systems will be an effective strategy to fabricate advanced functional membranes and worth attempting and testing. The presence of supramolecular assemblies by introducing appropriate guest molecules can impart membranes with other fascinating properties. A detailed understanding of the supramolecular structure, properties, and host-guest interactions will greatly assist in the rational design and synthesis of macrocycle-based membranes, as well as in developing their applications for various areas.

Overall, macrocycles have many advantages and hold great potential in membrane separation. The marriage of macrocycles with membranes will provide new opportunities in membrane science with a diversity that has not been fully explored yet. Although macrocycle-based membranes still face limitations and challenges, gratifying efforts by scientists have already provided a reference cornerstone for advanced construction of promising systems with diverse advantages. Continuous efforts in this research field will soon greatly stimulate the development of more advanced macrocycle-based membranes along with novel applications.

\section{Conflicts of interest}

There are no conflicts to declare.

\section{References}

1 W. J. Koros and C. Zhang, Nat. Mater., 2017, 16, 289-297.

2 S. P. Nunes, P. Z. Culfaz-Emecen, G. Z. Ramon, T. Visser, G. H. Koops, W. Jin and M. Ulbricht, J. Membr. Sci., 2020, 598.

3 X. Q. Cheng, Z. X. Wang, X. Jiang, T. Li, C. H. Lau, Z. Guo, J. Ma and L. Shao, Prog. Mater. Sci., 2018, 92, 258-283.

4 H. B. Park, J. Kamcev, L. M. Robeson, M. Elimelech and B. D. Freeman, Science, 2017, 356.

5 L. M. Robeson, J. Membr. Sci., 2008, 320, 390-400.

6 C. Zhang, B.-H. Wu, M.-Q. Ma, Z. Wang and Z.-K. Xu, Chem. Soc. Rev., 2019, 48, 3811-3841.

7 M. S. Denny Jr, J. C. Moreton, L. Benz and S. M. Cohen, Nat. Rev. Mater., 2016, 1, 1-17.

8 Y. Peng and W. Yang, Nat. Rev. Mater., 2020, 7, 1-17.

9 E. Barankova, X. Tan, L. F. Villalobos, E. Litwiller and K. V. Peinemann, Angew. Chem., 2017, 129, 3011-3014.

10 H. Fan, J. Gu, H. Meng, A. Knebel and J. Caro, Angew. Chem., Int. Ed., 2018, 57, 4083-4087.

11 D. B. Shinde, G. Sheng, X. Li, M. Ostwal, A.-H. Emwas, K.-W. Huang and Z. Lai, J. Am. Chem. Soc., 2018, 140, 14342-14349.

12 L. Chen, G. Shi, J. Shen, B. Peng, B. Zhang, Y. Wang, F. Bian, J. Wang, D. Li, Z. Qian, G. Xu, G. Liu, J. Zeng, L. Zhang, Y. Yang, G. Zhou, M. Wu, W. Jin, J. Li and H. Fang, Nature, 2017, 550, 415-418.

13 M. Y. Jeon, D. Kim, P. Kumar, P. S. Lee, N. Rangnekar, P. Bai, M. Shete, B. Elyassi, H. S. Lee, K. Narasimharao, S. N. Basahel, S. Al-Thabaiti, W. Xu, H. J. Cho, E. O. Fetisov, R. Thyagarajan, R. F. DeJaco, W. Fan, K. A. Mkhoyan, J. I. Siepmann and M. Tsapatsis, Nature, 2017, 543, 690.

14 Y. D. Cheng, Y. P. Ying, S. Japip, S. D. Jiang, T. S. Chung, S. Zhang and D. Zhao, Adv. Mater., 2018, 30, 1802401.

15 Z. C. Liu, S. K. M. Nalluri and J. F. Stoddart, Chem. Soc. Rev., 2017, 46, 2459-2478.

16 D. H. Zhao and J. S. Moore, Chem. Commun., 2003, 807-818, DOI: $10.1039 / \mathrm{b} 207442 \mathrm{~g}$.

17 W. Zhang and J. S. Moore, Angew. Chem., Int. Ed., 2006, 45, 4416-4439.

18 Y. Jin, A. Zhang, Y. Huang and W. Zhang, Chem. Commun., 2010, 46, 8258-8260.

19 G. Crini, Chem. Rev., 2014, 114, 10940-10975.

20 J. Szejtli, Chem. Rev., 1998, 98, 1743-1753.

21 Y. Zhou, K. Jie, R. Zhao and F. Huang, Adv. Mater., 2020, 32, 1904824.

22 G. W. Gokel, W. M. Leevy and M. E. Weber, Chem. Rev., 2004, 104, 2723-2750.

23 S. Li and W. C. Purdy, Chem. Rev., 1992, 92, 1457-1470.

24 A. Ikeda and S. Shinkai, Chem. Rev., 1997, 97, 1713-1734.

25 Y. Yu, J. Li, M. Zhang, L. Cao and L. Isaacs, Chem. Commun., 2015, 51, 3762-3765.

26 T. Ogoshi, T.-a. Yamagishi and Y. Nakamoto, Chem. Rev., 2016, 116, 7937-8002. 
27 D. A. Fowler, J. Tian, C. Barnes, S. J. Teat and J. L. Atwood, CrystEngComm, 2011, 13, 1446-1449.

28 C. Gropp, B. L. Quigley and F. o. Diederich, J. Am. Chem. Soc., 2018, 140, 2705-2717.

29 S. Maleknia and J. Brodbelt, J. Am. Chem. Soc., 1992, 114, 4295-4298.

30 M. V. Rekharsky and Y. Inoue, Chem. Rev., 1998, 98, 18751918.

31 H.-J. Schneider and U. Schneider, J. Inclusion Phenom. Mol. Recognit. Chem., 1994, 19, 67-83.

32 W. L. Mock and N. Y. Shih, J. Org. Chem., 1986, 51, 44404446.

33 H. Zhang and Y. Zhao, Chem. -Eur. J., 2013, 19, 1686216879.

34 V. Montes-García, J. Pérez-Juste, I. Pastoriza-Santos and L. M. Liz-Marzán, Chem. -Eur. J., 2014, 20, 10874-10883.

35 M. Wiemann and P. Jonkheijm, Isr. J. Chem., 2018, 58, 314325.

36 Q. Bian, W. Wang, S. Wang and G. Wang, ACS Appl. Mater. Interfaces, 2016, 8, 27360-27367.

37 H. Yang, B. Yuan, X. Zhang and O. A. Scherman, Acc. Chem. Res., 2014, 47, 2106-2115.

38 G. Zhang, B. Hua, A. Dey, M. Ghosh, B. A. Moosa and N. M. Khashab, Acc. Chem. Res., 2020, 14571-14575.

39 B. Zheng, F. Wang, S. Dong and F. Huang, Chem. Soc. Rev., 2012, 41, 1621-1636.

40 T. L. Price Jr and H. W. Gibson, Supramol. Polym. Chem., 2011, 151-182.

41 C. J. Pedersen, Science, 1988, 241, 536-540.

$42 \mathrm{~J}$. Lamb, R. Izatt, J. Christensen and D. Eatough, Thermodynamics and Kinetics of Cation-Macrocycle Interaction, ed. G. A. Melson, Plenum Press, New York, 1979, p. 145.

43 R. G. Pearson, J. Am. Chem. Soc., 1963, 85, 3533-3539.

44 Y. Takeda, H. Yano, M. Ishibashi and H. Isozumi, Bull. Chem. Soc. Jpn., 1980, 53, 72-76.

45 D. Marji, K. Abbas, R. Saymeh and Z. Taha, J. Inclusion Phenom. Macrocyclic Chem., 1999, 34, 49-56.

46 G. Rounaghi and E. Razavipanah, J. Inclusion Phenom. Macrocyclic Chem., 2008, 61, 313-318.

47 R. M. Izatt, J. S. Bradshaw, S. A. Nielsen, J. D. Lamb, J. J. Christensen and D. Sen, Chem. Rev., 1985, 85, 271-339.

48 C. Srivanavit, J. I. Zink and J. J. Dechter, J. Am. Chem. Soc., 1977, 99, 5876-5881.

49 V. Gutmann, Donor-acceptor Approach to Molecular Interactions, Plenum Press, 1978.

50 D. Xia and M. Xue, Polym. Chem., 2014, 5, 5591-5597.

51 D. Xia, J. Ma and P. Wang, Sens. Actuators, B, 2019, 279, 197203.

52 P. Wang, Z. Gao, M. Yuan, J. Zhu and F. Wang, Polym. Chem., 2016, 7, 3664-3668.

53 J. Chen, X. Yan, X. Chi, X. Wu, M. Zhang, C. Han, B. Hu, Y. Yu and F. Huang, Polym. Chem., 2012, 3, 3175-3179.

54 X. Yan, D. Xu, X. Chi, J. Chen, S. Dong, X. Ding, Y. Yu and F. Huang, Adv. Mater., 2012, 24, 362-369.

55 W. Jiang, A. Schäfer, P. C. Mohr and C. A. Schalley, J. Am. Chem. Soc., 2010, 132, 2309-2320.
56 J. Wu, K. C. F. Leung, D. Benítez, J. Y. Han, S. J. Cantrill, L. Fang and J. F. Stoddart, Angew. Chem., Int. Ed., 2008, 47, 7470-7474.

57 S. Dong, Y. Luo, X. Yan, B. Zheng, X. Ding, Y. Yu, Z. Ma, Q. Zhao and F. Huang, Angew. Chem., Int. Ed., 2011, 50, 1905-1909.

58 X. Ji, K. Jie, S. C. Zimmerman and F. Huang, Polym. Chem., 2015, 6, 1912-1917.

59 D. Liu, D. Wang, M. Wang, Y. Zheng, K. Koynov, G. n. K. Auernhammer, H.-J. r. Butt and T. Ikeda, Macromolecules, 2013, 46, 4617-4625.

60 W. Wang and H. Xing, Polym. Chem., 2018, 9, 2087-2091.

61 T. Shinbo, T. Yamaguchi, K. Nishimura and M. Sugiura, J. Chromatogr. A, 1987, 405, 145-153.

62 J. Szejtli, Chem. Rev., 1998, 98, 1743-1754.

63 N. Morin-Crini, P. Winterton, S. Fourmentin, L. D. Wilson, E. Fenyvesi and G. Crini, Prog. Polym. Sci., 2018, 78, 1-23.

64 A. Gentili, J. Chromatogr. A, 2020, 1609, 460654.

65 Q. Liu, Y. Zhou, J. Lu and Y. Zhou, Chemosphere, 2020, 241, 125043.

66 X. Yao, J. Mu, L. Zeng, J. Lin, Z. Nie, X. Jiang and P. Huang, Mater. Horiz., 2019, 6, 846-870.

67 B. Tian, S. Hua and J. Liu, Carbohydr. Polym., 2020, 232, 115805.

68 F. Hapiot, H. Bricout, S. Menuel, S. Tilloy and E. Monflier, Catal. Sci. Technol., 2014, 4, 1899-1908.

69 A. Alsbaiee, B. J. Smith, L. Xiao, Y. Ling, D. E. Helbling and W. R. Dichtel, Nature, 2016, 529, 190-194.

70 H. Li, B. Meng, S.-H. Chai, H. Liu and S. Dai, Chem. Sci., 2016, 7, 905-909.

71 I. Uemasu, J. Inclusion Phenom., 1992, 13, 1-7.

72 H. Yang and Y. Hu, Chem. Eng. Process., 2017, 116, 114-120.

73 K. Balogh, N. Szaniszlo, H. Klára and E. Fenyvesi, J. Inclusion Phenom. Macrocyclic Chem., 2007, 57, 457-462.

74 R. Q. Wang, X. B. Wei and Y. Q. Feng, Chem. -Eur. J., 2018, 24, 10979-10983.

75 R. A. Smaldone, R. S. Forgan, H. Furukawa, J. J. Gassensmith, A. M. Slawin, O. M. Yaghi and J. F. Stoddart, Angew. Chem., Int. Ed., 2010, 49, 8630-8634.

76 D. Wu, J. J. Gassensmith, D. Gouvêa, S. Ushakov, J. F. Stoddart and A. Navrotsky, J. Am. Chem. Soc., 2013, 135, 6790-6793.

77 J. J. Gassensmith, H. Furukawa, R. A. Smaldone, R. S. Forgan, Y. Y. Botros, O. M. Yaghi and J. F. Stoddart, J. Am. Chem. Soc., 2011, 133, 15312-15315.

78 D. Gutsche, in Calixarenes in the Nanoworld, Springer, 2007, pp. 1-19.

79 R. Kumar, Y. O. Lee, V. Bhalla, M. Kumar and J. S. Kim, Chem. Soc. Rev., 2014, 43, 4824-4870.

80 D.-S. Guo, V. D. Uzunova, X. Su, Y. Liu and W. M. Nau, Chem. Sci., 2011, 2, 1722-1734.

81 A. Casnati, F. Sansone and R. Ungaro, Acc. Chem. Res., 2003, 36, 246-254.

82 H. Yamamoto and S. Shinkai, Chem. Lett., 1994, 23, 11151118.

83 J. L. Atwood, L. J. Barbour and A. Jerga, Science, 2002, 296, 2367-2369. 
84 N. Morohashi, A. Tonosaki, T. Kitagawa, T. Sasaki, K. Ebata and T. Hattori, Cryst. Growth Des., 2017, 17, 5038-5043.

85 S. A. Herbert, A. Janiak, P. K. Thallapally, J. L. Atwood and L. J. Barbour, Chem. Commun., 2014, 50, 15509-15512.

86 G. S. Ananchenko, I. L. Moudrakovski, A. W. Coleman and J. A. Ripmeester, Angew. Chem., 2008, 120, 5698-5700.

87 Y. V. Shalaeva, J. E. Morozova, D. A. Mironova, E. K. Kazakova, M. T. Kadirov, I. R. Nizameev and A. I. Konovalov, Supramol. Chem., 2015, 27, 595-605.

88 M. M. Lakouraj and H. Tashakkorian, Supramol. Chem., 2013, 25, 221-232.

89 H. Guo, F. Yang, X. Chai, Z. Jiao and C. Li, Iran. Polym. J., 2012, 21, 451-456.

90 D. Shetty, S. Boutros, T. Skorjanc, B. Garai, Z. Asfari, J. Raya and A. Trabolsi, J. Mater. Chem. A, 2020, 8, 13942-13945.

91 D. Shetty, J. Raya, D. S. Han, Z. Asfari, J.-C. Olsen and A. Trabolsi, Chem. Mater., 2017, 29, 8968-8972.

92 Z. Zhang, L. Li, D. An, H. Li and X. Zhang, J. Mater. Sci., 2020, 55, 1854-1864.

93 K. Su, W. Wang, B. Li and D. Yuan, ACS Sustainable Chem. Eng., 2018, 6, 17402-17409.

94 D. An, L. Li, Z. Zhang, A. M. Asiri, K. A. Alamry and X. Zhang, Mater. Chem. Phys., 2020, 239, 122328.

95 J. V. Prata, A. I. Costa, G. Pescitelli and H. D. Pinto, Polym. Chem., 2014, 5, 5793-5803.

96 Z. Zhang, Y. Luo, J. Chen, S. Dong, Y. Yu, Z. Ma and F. Huang, Angew. Chem., Int. Ed., 2011, 50, 1397-1401.

97 M. Xue, Y. Yang, X. Chi, Z. Zhang and F. Huang, Acc. Chem. Res., 2012, 45, 1294-1308.

98 L. Chen, Y. Cai, W. Feng and L. Yuan, Chem. Commun., 2019, 55, 7883-7898.

99 K. Yang, Y. Pei, J. Wen and Z. Pei, Chem. Commun., 2016, 52, 9316-9326.

100 L. L. Tan, H. Li, Y. Tao, S. X. A. Zhang, B. Wang and Y. W. Yang, Adv. Mater., 2014, 26, 7027-7031.

101 L.-L. Tan, Y. Zhu, Y. Jin, W. Zhang and Y.-W. Yang, Supramol. Chem., 2018, 30, 648-654.

102 T. Ogoshi, R. Sueto, K. Yoshikoshi, Y. Sakata, S. Akine and T. a. Yamagishi, Angew. Chem., 2015, 127, 9987-9990.

103 T. Ogoshi, K. Saito, R. Sueto, R. Kojima, Y. Hamada, S. Akine, A. M. P. Moeljadi, H. Hirao, T. Kakuta and T. a. Yamagishi, Angew. Chem., Int. Ed., 2018, 57, 15921595.

104 K. Jie, M. Liu, Y. Zhou, M. A. Little, S. Bonakala, S. Y. Chong, A. Stephenson, L. Chen, F. Huang and A. I. Cooper, J. Am. Chem. Soc., 2017, 139, 2908-2911.

105 K. Jie, M. Liu, Y. Zhou, M. A. Little, A. Pulido, S. Y. Chong, A. Stephenson, A. R. Hughes, F. Sakakibara and T. Ogoshi, J. Am. Chem. Soc., 2018, 140, 6921-6930.

106 K. Jie, Y. Zhou, E. Li, R. Zhao and F. Huang, Angew. Chem., Int. Ed., 2018, 57, 12845-12849.

107 M. Wang, J. Zhou, E. Li, Y. Zhou, Q. Li and F. Huang, J. Am. Chem. Soc., 2019, 141, 17102-17106.

108 X. Sheng, E. Li, Y. Zhou, R. Zhao, W. Zhu and F. Huang, J. Am. Chem. Soc., 2020, 142, 6360-6364.

109 E. Li, Y. Zhou, R. Zhao, K. Jie and F. Huang, Angew. Chem., Int. Ed., 2019, 58, 3981-3985.
110 J. R. Wu, B. Li and Y. W. Yang, Angew. Chem., 2020, 132, 2271-2275.

111 W. Yang, K. Samanta, X. Wan, T. U. Thikekar, Y. Chao, S. Li, K. Du, J. Xu, Y. Gao and H. Zuilhof, Angew. Chem., Int. Ed., 2020, 59, 3994-3999.

112 S. J. Barrow, S. Kasera, M. J. Rowland, J. del Barrio and O. A. Scherman, Chem. Rev., 2015, 115, 12320-12406.

113 R. S. Cicolani, L. R. R. Souza, G. B. de Santana Dias, J. M. R. Gonçalves, I. d. S. Abrahao, V. M. Silva and G. J. F. Demets, J. Inclusion Phenom. Macrocyclic Chem., 2021, 99, 1-12.

114 G. Zhang, A.-H. Emwas, U. F. S. Hameed, S. T. Arold, P. Yang, A. Chen, J.-F. Xiang and N. M. Khashab, Chem, 2020, 6, 1082-1096.

115 Q. Li, K. Jie and F. Huang, Angew. Chem., 2020, 132, 53935396.

116 J. Liang, A. Nuhnen, S. Millan, H. Breitzke, V. Gvilava, G. Buntkowsky and C. Janiak, Angew. Chem., 2020, 132, 6124-6129.

117 J. Liang, S. Xing, P. Brandt, A. Nuhnen, C. Schlüsener, Y. Sun and C. Janiak, J. Mater. Chem. A, 2020, 8, 1979919804.

118 J. Gawroński, H. Kołbon, M. Kwit and A. Katrusiak, J. Org. Chem., 2000, 65, 5768-5773.

119 J. Gawroński, K. Gawronska, J. Grajewski, M. Kwit, A. Plutecka and U. Rychlewska, Chem. -Eur. J., 2006, 12, 1807-1817.

120 K. Tanaka and S. Hachiken, Tetrahedron Lett., 2008, 49, 2533-2536.

121 K. Tanaka, A. Asakura, T. Muraoka, P. Kalicki and Z. Urbanczyk-Lipkowska, New J. Chem., 2013, 37, 28512855.

122 K. Tanaka, N. Fukuda and T. Fujiwara, Tetrahedron: Asymmetry, 2007, 18, 2657-2661.

123 T. Ema, J. Inclusion Phenom. Macrocyclic Chem., 2012, 74, 41-55.

124 A. Chaix, G. Mouchaham, A. Shkurenko, P. Hoang, B. Moosa, P. M. Bhatt, K. Adil, K. N. Salama, M. Eddaoudi and N. M. Khashab, J. Am. Chem. Soc., 2018, 140, 1457114575.

125 A. Dey, S. Chand, L. O. Alimi, M. Ghosh, L. Cavallo and N. M. Khashab, J. Am. Chem. Soc., 2020, 142, 15823-15829.

126 S. J. Lue and S. Peng, J. Membr. Sci., 2003, 222, 203-217.

127 E. Fontananova, A. Basile, A. Cassano and E. Drioli, J. Inclusion Phenom. Macrocyclic Chem., 2003, 47, 33-37.

128 S. P. Kusumocahyo, T. Kanamori, K. Sumaru, T. Iwatsubo and T. Shinbo, J. Membr. Sci., 2004, 231, 127-132.

129 S. Touil, S. Tingry, J. Palmeri, S. Bouchtalla and A. Deratani, Polymer, 2005, 46, 9615-9625.

130 H. L. Chen, L. G. Wu, J. Tan and C. L. Zhu, Chem. Eng. J., 2000, 78, 159-164.

131 L. Y. Jiang and T. S. Chung, J. Membr. Sci., 2010, 346, 45-58.

132 L. Zhang, L. L. Li, N. J. Liu, H. L. Chen, Z. R. Pan and S. J. Lue, AIChE J., 2013, 59, 604-612.

133 S. Tan, Q. Fu, J. M. P. Scofield, J. Kim, P. A. Gurr, K. Ladewig, A. Blencowe and G. G. Qiao, J. Mater. Chem. A, 2015, 3, 14876-14886. 
134 H. Mao, H. Q. Zhang, Y. F. Li, Y. B. Xue, F. Pei, J. T. Wang and J. D. Liu, ACS Sustainable Chem. Eng., 2015, 3, 19251933.

135 A. M. Abou-Elanwar, Y. M. Shirke, P. G. Ingole, W. K. Choi, H. Lee, S. U. Hong, H. K. Lee and J. D. Jeon, J. Mater. Chem. A, 2018, 6, 24569-24579.

136 X.-L. Cao, J.-L. Guo, J. Cai, M.-L. Liu, S. Japip, W. Xing and S.-P. Sun, AIChE J., 2020, 66, e16879.

137 J. Cai, X.-L. Cao, Y. Zhao, F.-Y. Zhou, Z. Cui, Y. Wang and S.-P. Sun, J. Membr. Sci., 2020, 600.

138 Y. Xiao, H. M. Lim, T. S. Chung and R. Rajagopalan, Langmuir, 2007, 23, 12990-12996.

139 Y. C. Xiao and T. S. Chung, J. Membr. Sci., 2007, 290, 78-85. 140 Z. Z. Zhou, Y. C. Xiao, T. A. Hatton and T. S. Chung, J. Membr. Sci., 2009, 339, 21-27.

141 Y. He, J. Miao, Z. Jiang, K. Tu, H. Yang, S. Chen, L. Zhang and R. Zhang, Sci. Rep., 2019, 9, 12435.

142 Z. Liu, F. Luo, X. J. Ju, R. Xie, T. Luo, Y. M. Sun and L. Y. Chu, Adv. Funct. Mater., 2012, 22, 4742-4750.

143 Y. Liu, P. Li, L. Xie, D. Y. Fan and S. S. Huang, J. Membr. Sci., 2014, 453, 12-17.

144 Y. L. Kang, J. Zhang, G. Wu, M. X. Zhang, S. C. Chen and Y. Z. Wang, ACS Sustainable Chem. Eng., 2018, 6, 1178311792.

145 H. Zhai, R. Qu, X. Li, Y. Liu, Y. Wei and L. Feng, J. Mater. Chem. A, 2020, 8, 2684-2690.

146 L. Ren, J. Chen, Q. Lu, J. Han and H. Wu, ACS Appl. Mater. Interfaces, 2020, 12, 52050-52058.

147 S. Xu, P. Wang, Z. Sun, C. Liu, D. Lu, J. Qi and J. Ma, J. Membr. Sci., 2019, 569, 124-136.

148 A. Alsbaiee, B. J. Smith, L. L. Xiao, Y. H. Ling, D. E. Helbling and W. R. Dichtel, Nature, 2016, 529, 190-194.

149 D. M. Alzate-Sanchez, B. J. Smith, A. Alsbaiee, J. P. Hinestroza and W. R. Dichtel, Chem. Mater., 2016, 28, 8340-8346.

150 E. E. Leonhardt, M. A. B. Meador and K. L. Wooley, Chem. Mater., 2018, 30, 6226-6230.

151 H. Wu, B. Tang and P. Wu, J. Membr. Sci., 2013, 428, 301308.

152 Z. X. Yu, Y. Pan, Y. He, G. Y. Zeng, H. Shi and H. H. Di, RSC Adv., 2015, 5, 51364-51370.

153 L. F. Villalobos, T. F. Huang and K. V. Peinemann, Adv. Mater., 2017, 29, 1606641.

154 T. Huang, T. Puspasari, S. P. Nunes and K.-V. Peinemann, Adv. Funct. Mater., 2020, 30.

155 Q. Zhao and Y. Liu, Chem. Commun., 2018, 54, 7362-7365.

156 T. Huang, B. A. Moosa, P. Hoang, J. Liu, S. Chisca, G. Zhang, M. AlYami, N. M. Khashab and S. P. Nunes, Nat. Commun., 2020, 11, 1-10.

157 L. Yue, S. Wang, D. Zhou, H. Zhang, B. Li and L. Wu, Nat. Commun., 2016, 7, 10742.

158 G. Zhang, B. Li, Y. Zhou, X. Chen, B. Li, Z.-Y. Lu and L. Wu, Nat. Commun., 2020, 11, 1-9.

159 Y. Zhou, G. Zhang, B. Li and L. Wu, ACS Appl. Mater. Interfaces, 2020, 12, 30761-30769.

160 B. Tieke, A. Toutianoush and W. Q. Jin, Adv. Colloid Interface Sci., 2005, 116, 121-131.
161 A. Toutianoush, A. El-Hashani, J. Schnepf and B. Tieke, Appl. Surf. Sci., 2005, 246, 430-436.

162 A. Toutianoush, J. Schnepf, A. El Hashani and B. Tieke, Adv. Funct. Mater., 2005, 15, 700-708.

163 A. El-Hashani and B. Tieke, J. Nanosci. Nanotechnol., 2006, 6, 1710-1717.

164 B. Tieke, A. El-Hashani, A. Toutianoush and A. Fendt, Thin Solid Films, 2008, 516, 8814-8820.

165 M. Kazemabad, A. Verliefde, E. R. Cornelissen and A. D'Haese, J. Membr. Sci., 2020, 595.

166 Y.-x. Shen, W. C. Song, D. R. Barden, T. Ren, C. Lang, H. Feroz, C. B. Henderson, P. O. Saboe, D. Tsai, H. Yan, P. J. Butler, G. C. Bazan, W. A. Phillip, R. J. Hickey, P. S. Cremer, H. Vashisth and M. Kumar, Nat. Commun., 2018, 9, 2294.

167 T. Huang, Y. Niu, F. Zhang, L. Zhang, S. Chen and Q. J. Yu, Appl. Mater. Today, 2017, 9, 176-183.

168 X. Yan, V. Janout, J. T. Hsu and S. L. Regen, J. Am. Chem. Soc., 2002, 124, 10962-10963.

169 X. Yan, V. Janout, J. T. Hsu and S. L. Regen, J. Am. Chem. Soc., 2003, 125, 8094-8095.

170 J. W. Li, V. Janout, D. H. McCullough, J. T. Hsu, Q. Truong, E. Wilusz and S. L. Regen, Langmuir, 2004, 20, 8214-8219.

171 D. H. McCullough, V. Janout, J. W. Li, J. T. Hsu, Q. Truong, E. Wilusz and S. L. Regen, J. Am. Chem. Soc., 2004, 126, 9916-9917.

172 J. W. Li, V. Janout and S. L. Regen, Langmuir, 2005, 21, 1676-1678.

173 J. W. Li, V. Janout and S. L. Regen, J. Am. Chem. Soc., 2006, 128, 682-683.

174 D. H. McCullough III, R. Grygorash, J. T. Hsu and S. L. Regen, J. Am. Chem. Soc., 2007, 129, 8663-8667.

175 Y. Wang, V. Janout and S. L. Regen, Macromolecules, 2008, 41, 497-500.

176 M. Wang, V. Janout and S. L. Regen, Langmuir, 2010, 26, 12988-12993.

177 M. Wang, V. Janout and S. L. Regen, Chem. Commun., 2011, 47, 2387-2389.

178 M. Wang, V. Janout and S. L. Regen, Langmuir, 2012, 28, 4614-4617.

179 M. Wang, S. Yi, V. Janout and S. L. Regen, Chem. Mater., 2013, 25, 3785-3787.

180 M. D. Conner, V. Janout, I. Kudelka, P. Dedek, J. Y. Zhu and S. L. Regen, Langmuir, 1993, 9, 2389-2397.

181 R. A. Hendel, L. H. Zhang, V. Janout, M. D. Conner, J. T. Hsu and S. L. Regen, Langmuir, 1998, 14, 6545-6549.

182 M. Conner, V. Janout and S. L. Regen, J. Am. Chem. Soc., 1993, 115, 1178-1180.

183 R. A. Hendel, E. Nomura, V. Janout and S. L. Regen, J. Am. Chem. Soc., 1997, 119, 6909-6918.

184 S. M. Sanip, A. F. Ismail, P. S. Goh, T. Soga, M. Tanemura and H. Yasuhiko, Sep. Purif. Technol., 2011, 78, 208-213.

185 A. L. Ahmad, Z. A. Jawad, S. C. Low and S. H. S. Zein, J. Membr. Sci., 2014, 451, 55-66.

186 Z. V. Singh, L.-L. Tan, M. G. Cowan, Y.-W. Yang, W. Zhang, D. L. Gin and R. D. Noble, J. Membr. Sci., 2017, 539, 224228. 
187 P. P. Chapala, M. V. Bermeshev, L. E. Starannikova, V. P. Shantarovich, N. N. Gavrilova, V. G. Avakyan, M. P. Filatova, Y. P. Yampolskii and E. S. Finkelshtein, J. Membr. Sci., 2015, 474, 83-91.

188 A. Nadeali, M. Z. Pedram, M. Omidkhah and M. Yarmohammadi, ACS Sustainable Chem. Eng., 2019, 7, 19015-19026.

189 J. T. Liu, Y. C. Xiao, K. S. Liao and T. S. Chung, J. Membr. Sci., 2017, 523, 92-102.

190 D. Wu, C. Yi, Y. Wang, S. Qi and B. Yang, J. Membr. Sci., 2018, 551, 191-203.

191 J. Wu, J. Liu and T.-S. Chung, Adv. Sustainable Syst., 2018, 2, 1800044.

192 P. Chen, H. W. Liang, X. H. Lv, H. Z. Zhu, H. B. Yao and S. H. Yu, ACS Nano, 2011, 5, 5928-5935.

193 M. Chen, C. Wang, W. Fang, J. Wang, W. Zhang, G. Jin and G. Diao, Langmuir, 2013, 29, 11858-11867.

194 C. Chen, F. Liu, X. Zhang, Z. Zhao and S. Liu, Beilstein J. Org. Chem., 2019, 15, 992-999.

195 R. Zhao, Y. Wang, X. Li, B. L. Sun and C. Wang, ACS Appl. Mater. Interfaces, 2015, 7, 26649-26657.

196 M. M. Teng, F. T. Li, B. R. Zhang and A. A. Taha, Colloids Surf., A, 2011, 385, 229-234.

197 A. Celebioglu, Z. I. Yildiz and T. Uyar, Sci. Rep., 2017, 7, 7369.

198 Z. Z. Wei, Y. L. Liu, H. M. Hu, J. Y. Yu and F. X. Li, RSC Adv., 2016, 6, 108240-108246.

199 A. Giwa and S. W. Hasan, J. Membr. Sci., 2018, 563, 914-925.

200 Z. Wang, B. Zhang, C. Fang, Z. Liu, J. Fang and L. Zhu, Carbohydr. Polym., 2019, 222.
201 F. V. Adams, E. N. Nxumalo, R. W. M. Krause, E. M. V. Hoek and B. B. Mamba, J. Membr. Sci., 2012, 405, 291-299.

202 F. V. Adams, D. S. Dlamini, E. N. Nxumalo, R. W. M. Krause, E. M. V. Hoek and B. B. Mamba, J. Membr. Sci., 2013, 429, 58-65.

203 F. V. Adams, E. N. Nxumalo, R. W. M. Krause, E. M. V. Hoek and B. B. Mamba, J. Appl. Polym. Sci., 2013, 130, 2005-2014.

204 E. Salimi, A. Ghaee and A. F. Ismail, Mater. Lett., 2018, 215, 276-279.

205 Z. Wang, S. Guo, B. Zhang and L. Zhu, J. Membr. Sci., 2019, 592.

206 K. Baek, D. Xu, J. Murray, S. Kim and K. Kim, Chem. Commun., 2016, 52, 9676-9678.

207 S. P. Malinga, O. A. Arotiba, R. W. M. Krause, S. F. Mapolie, M. S. Diallo and B. B. Mamba, Sep. Sci. Technol., 2013, 48, 2724-2734.

208 J. Xue, Z. W. Jiao, R. Bi, R. N. Zhang, X. D. You, F. Wang, L. J. Zhou, Y. L. Su and Z. Y. Jiang, J. Membr. Sci., 2019, 584, 282-289.

209 L. Y. Jiang and T. S. Chung, J. Membr. Sci., 2009, 327, 216225.

210 L. Liu, Z. Jiang, F. Pan, F. Peng and H. Wu, J. Membr. Sci., 2006, 279, 111-119.

211 Y. Wang, T. S. Chung and H. Wang, AIChE J., 2011, 57, 1470-1484.

212 Z. Zhai, C. Jiang, N. Zhao, W. Dong, P. Li, H. Sun and Q. J. Niu, J. Membr. Sci., 2020, 595.

213 B. Li, S. Japip and T.-S. Chung, Nat. Commun., 2020, 11, 1198.

214 K. Singh, P. G. Ingole, H. C. Bajaj and H. Gupta, Desalination, 2012, 298, 13-21. 